OPEN ACCESS

Edited by:

Syed Nasir Abbas Bukhari, Al Jouf University, Saudi Arabia

Reviewed by: Wolfgang Schuehly, University of Graz, Austria Corrado Tringali, University of Catania, Italy

${ }^{*}$ Correspondence:

Ying Song

songying6224@163.com

Specialty section:

This article was submitted to Experimental Pharmacology and Drug

Discovery,

a section of the journal

Frontiers in Pharmacology

Received: 24 November 2020 Accepted: 15 February 2021

Published: 17 March 2021

Citation:

Lin Y, Li Y, Zeng Y, Tian B, Qu X, Yuan $Q$ and Song $Y(2021)$ Pharmacology, Toxicity, Bioavailability, and Formulation of Magnolol:

An Update

Front. Pharmacol. 12:632767. doi: 10.3389/fphar.2021.632767

\section{Pharmacology, Toxicity, Bioavailability, and Formulation of Magnolol: An Update}

\author{
Yiping Lin ${ }^{1}$, Yuke $L i^{1}$, Yuanlian Zeng ${ }^{1}$, Bin Tian ${ }^{1}$, Xiaolan $Q u^{1}$, Qianghua Yuan ${ }^{2}$ and \\ Ying Song ${ }^{2 *}$ \\ ${ }^{1}$ School of Pharmacy, Chengdu University of Traditional Chinese Medicine, Chengdu, China, ${ }^{2}$ Affiliated Hospital of Chengdu \\ University of Traditional Chinese Medicine, Chengdu, China
}

Magnolol (MG) is one of the primary active components of Magnoliae officinalis cortex, which has been widely used in traditional Chinese and Japanese herbal medicine and possesses a wide range of pharmacological activities. In recent years, attention has been drawn to this component due to its potential as an anti-inflammatory and antitumor drug. To summarize the new biological and pharmacological data on MG, we screened the literature from January 2011 to October 2020. In this review, we provide an actualization of already known anti-inflammatory, cardiovascular protection, antiangiogenesis, antidiabetes, hypoglycemic, antioxidation, neuroprotection, gastrointestinal protection, and antibacterial activities of MG. Besides, results from studies on antitumor activity are presented. We also summarized the molecular mechanisms, toxicity, bioavailability, and formulations of MG. Therefore, we provide a valid cognition of MG.

Keywords: magnolol, pharmacology, toxicity, bioavailability, formulation

\section{INTRODUCTION}

Magnoliae officinalis cortex, which was first recorded in "Shennong Herbal Classic" (Qin and Han Dynasty, around 221 B.C. to 220 A.D.), is the dry bark, root bark, and branch bark of Magnolia officinalis Rehd. et Wils. or Magnolia officinalis Rehd. et Wils. var. biloba Rehd. et Wils. In traditional medicine, Magnoliae officinalis cortex mainly acts to dry dampness and disperse phlegm, lower Qi, and eliminate fullness. Clinically, it is commonly used to treat asthma, constipation, edema, abdominal distension, malaria, and other diseases by combining different traditional Chinese medicines. For example, the Da Houpo Pill is used to treat abdominal distension (Song Ji Zonglu). The Xiaochengqi decoction is used for the treatment of tidal fever, constipation, and abdominal pain (Treatise on Febrile Diseases). The Banxia Houpo decoction has therapeutic effects on chronic pharyngitis, chronic bronchitis, and esophageal fistula (Synopsis of the Golden Chamber). Recent studies have shown that Magnoliae officinalis cortex has multiple pharmacological activities on the nervous system (Lee et al., 2009; Lee et al., 2013), digestive system (Kim HJ et al., 2018), inflammation (Kim JY et al., 2018), and cancer (Kim et al., 2020). And, its neolignan compounds include MG (a), honokiol (b), 4-methylhonokiol (c), and (R)-8,9dihydroxydihydromagnolol (d) (Rempel et al., 2013) (Figure 1).

The isomers MG (5,5'-diallyl-2,2'-dihydroxybiphenyl) and honokiol (3,5'- diallyl-4,2'dihydroxybiphenyl) are biphenyl-type neolignans. They have been recognized as the principal active components of magnolia bark extract, usually accounted for 1-10\% of dry bark, depending on the Magnolia species (officinalis or obovata) and extraction method (Sarrica et al., 2018; Oufensou et al., 2019; tata et al., 2020). Talarek et al. reviewed the chemistry, bioavailability, and 


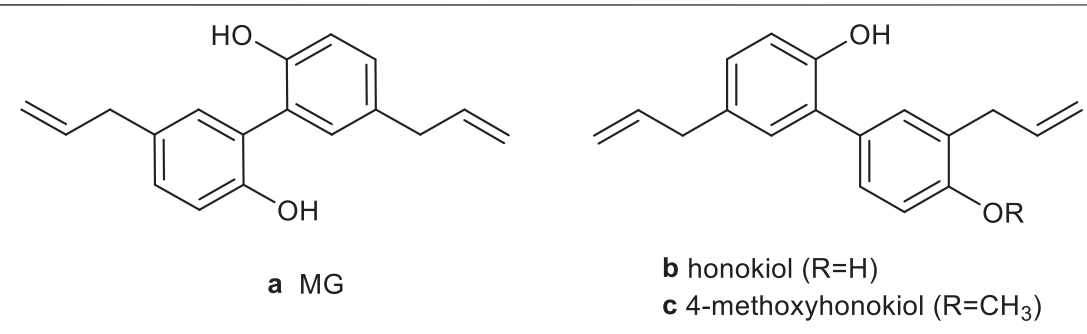<smiles>C=CCc1ccc(O)c(-c2cc(C[C@H](O)CO)ccc2O)c1</smiles>

d 8,9-dihydroxydihdromagnolol

FIGURE 1 | Chemical structure of the main neolignans of Magnoliae officinalis cortex.

neuroprotective activity of honokiol (Talarek et al., 2017). Woodbury et al. concluded that honokiol has therapeutic potential for anxiety, pain, cerebrovascular damage, epilepsy, and cognitive disorders (Woodbury et al., 2013). Ong et al. and Banik et al. summarized the antitumor mechanisms of honokiol, including the regulation of MAPK, NF- $\kappa \mathrm{B}$, HIF- $\alpha$, $\mathrm{PI} 3 \mathrm{~K} / \mathrm{Akt} / \mathrm{ERK} / \mathrm{mTOR}, \mathrm{Wnt} / \beta$-catenin epidermal growth factor receptor (EGFR), signal transduction and activator of transcription (STAF), and notch signaling pathways (Rauf et al., 2018; Banik et al., 2019; Ong et al., 2020). The metabolism, bioavailability, and pharmacological of honokiol were reviewed by Ong et al. (Ong et al., 2020). Additionally, the antiangiogenesis (Fried and Arbiser, 2009), antioxidation and antibacterial activities (Shen et al., 2010), and molecular mechanisms of honokiol have been summarized.

MG was first isolated from magnolia bark by Japanese scientist Sugii in 1930 and was first synthesized by Swedish scientist H. Erdtman and J. Runebeng with the p-allylphenol as raw material (Erdtman and Runeberg, 1957). However, the yield was only $25 \%$, and it was challenging to separate and purify. Zhang et al. used 2,2'-biphenol and 1-bromobutane as raw materials to prepare MG (Zhang and Sun, 2011). The reaction process was simple and effective with mild conditions as well as high product purity $(>98 \%)$, and the yield was increased to $60.2 \%$.

Numerous studies showed that MG possesses extensive biological activities, such as anti-inflammatory (Wei et al., 2014; Lin et al., 2015; Zhang L et al., 2018; Chen H et al., 2019), antitumor (McKeown et al., 2014; Zhang FH et al., 2017; Shen et al., 2017), cardiovascular protection (Liang CJ et al., 2014; Chang et al., 2018), antiangiogenesis (Kim GD et al., 2013; Chen et al., 2013), hypoglycemic (Pulvirenti et al., 2017; Suh et al., 2017; Parray et al., 2018), antioxidation (Baschieri et al., 2017), neuroprotection (Matsui et al., 2016; Kou et al., 2017; Xie et al., 2020), gastrointestinal protection (Chao et al., 2018), and antibacterial activities (Dong et al., 2017) (Table 1).
The studies about MG's toxicity have been done, suggesting that MG has no genotoxicity and mutagenic toxicity (Saito et al., 2006). As a phenolic polyhydroxy compound, MG's poor aqueous solubility and low oral bioavailability limit its clinical use. Therefore, various formulations such as liposomes (Shen et al., 2016), solid dispersions (Stefanache et al., 2017a), emulsions (Sheng et al., 2014), and nanoparticles (Wang et al., 2011) have been developed to ameliorate the water solubility and bioavailability of it.

In this review, the pharmacological activities and molecular mechanisms of MG are summarized and updated. Its toxicities, bioavailability, and formulations are reviewed, to identify the benefit of further studies on MG and to find the best method to improve its bioavailability.

\section{MATERIALS AND METHODS}

This article collected literature studies related to pharmacology, toxicity, bioavailability, and formulation of MG published from January 2011 to October 2020. All related information about MG was collected by using the keyword of magnolol from globally recognized scientific search engines and databases, such as Web of Science, Springer, ScienceDirect, Elsevier, Google Scholar, and Chinese National Knowledge Infrastructure (CNKI). The source information of Magnoliae officinalis cortex was provided by the 2020 edition of Chinese Pharmacopoeia. The pharmacological activities, molecular mechanisms, toxicity, bioavailability, and formulations of MG are summarized, and the deficiencies of current studies are discussed.

\section{PHARMACOLOGICAL ACTIVITY}

\section{Anti-Inflammatory Activity}

Inflammation is generally characterized by overexpression of inducible nitric oxide synthase (iNOS) and cyclooxygenase-2 
TABLE 1 | Modern pharmacological studies of MG

\begin{tabular}{ll}
\hline Effect & Model/targets \\
\hline $\begin{array}{l}\text { Anti-inflammatory } \\
\text { activity }\end{array}$ & LPS-induced RAW 264.7 cells
\end{tabular}

activity

MTT-induced U937 cells

C57Bᄂ/6 mice

DSS-induced male C57BL/6

mice

RAW 264.7 cells

LPS-induced mammary

tissues

LPS-induced mouse uterine

epithelial cells

LPS-induced BALB/c mice

LPS-induced SD rats

LPS-induced RAW 264.7 cells

Human FLS

Female Lewis rats

C57Bᄂ/6J mice

RAW 264.7 cells

A549 cells

Human aortic endothelial cells

Antitumor activity Cholangiocarcinoma (CCA) cells

BALB/c nude mice
5-FU, CDDP, and GEM $(40 \mu \mathrm{M})$ reduced cell survival

\section{Positive}

Dosage

In vitro: 5, 10,

and $15 \mu \mathrm{M}$

In vitro: $10-100 \mu \mathrm{M}$

DXM $\left(5 \mathrm{mg} \mathrm{kg}^{-1}\right)$ increased colon length relieved colon pathological injuries

DEX $\left(0.5 \mathrm{mg} \mathrm{kg}^{-1}\right)$ reduced the MPO activity

In vivo: 5,10 , and

$20 \mathrm{mg} \mathrm{kg}^{-1}$

(intragastric

administration)

In vivo: 25,50 , and

$100 \mathrm{mg} \mathrm{kg}^{-1}$ (gavage)

In vitro: 5, 10,

and $20 \mu \mathrm{M}$

In vitro: $12.5,25,50$,

100 , and $200 \mu^{-1}$

In vitro: $12.5,25$, and

$50 \mu \mathrm{gl}^{-1}$

In vivo: 5,10 , and

$20 \mathrm{mg} \mathrm{kg}^{-1}$ (i.p.

injection)

In vivo: 10 and

$20 \mathrm{mg} \mathrm{kg}^{-1}$ (i.p.

injection)

In vitro: 15,30 , and

$60 \mu \mathrm{g} \mathrm{ml}^{-1}$

In vitro: $2.5-25 \mu \mathrm{g} \mathrm{ml}^{-1}$

In vivo: $100 \mathrm{mg} \mathrm{kg}^{-1}$

(i.p. injection)

In vivo: 10,25 , and

$50 \mathrm{mg} \mathrm{kg}^{-1}$ (i.p.)

In vitro: 25, 50, and

$100 \mu \mathrm{M}$

In vitro: $6.25,12.5,25$

50,100 , and $200 \mu \mathrm{M}$

In vitro: $5 \mu \mathrm{M}$

In vitro: $20-160 \mu \mathrm{M}$

In vivo: $40 \mathrm{mg} \mathrm{kg}^{-1}$

(i.p. injection)

\section{Result/mechanism/method}

Inhibited iNOS and COX-2 expression and NF-kB activation via regulating PI3K/Akt and MAPK signaling pathways

Inhibited NO production and expression of $\mathrm{p}-\mathrm{kB} a, \mathrm{p}-\mathrm{P} 65$, IL- $\quad$ Chen $\mathrm{H}$ et al.

$1 \beta$, and TNF- $\alpha$. Downregulated phospho-JNK (p-JNK) and (2019) p-p38

Dose-dependently reduced TNF- $\alpha$, IL-1 $\beta$, and IL-6. Inhibited weight loss and colon shortening induced by dextran sulfate sodium (DSS)

Inhibited the expression of TNF- $\alpha$, IL-1 $\beta$, and IL-12 by

Shen $P$ et a

regulating NF-kB and PPAR- $\gamma$ pathways

Activated p38 MAPK and Nrf2/HO-1 cascade and promoted ROS production

Reduced phosphorylation of p65, p38, IkBa, JNK, and ERK. Inhibited TLR4 expression and production of TNF- $\alpha$, IL-1 $\beta$, and IL-6

Inhibited the expression of TLR4 and NF-kB and MAPKs activation

Attenuated mice mastitis tissue damage and MPO activity

Increased the expression of PPAR- $\gamma$. Altered

pneumonedema, neutrophil infiltration, ROS production,

NOS and COX-2 expression, NF-kB activation, and

proinflammatory factor level

Downregulated TLR4 expression, NF-kB and MAPK pathway Fu et al. (2013)

activation, and proinflammatory cytokine excretion. Dose-

dependently (30-60 $\mathrm{gg} \mathrm{m}^{-1}{ }^{-1}$ ) inhibited the IL-1 $\beta, \mathrm{IL}-6$, and

TNF- $\alpha$ expression. Suppressed IKB $a$ degradation and

phosphorylation of JNK, ERK, and p38

Suppressed cytokine expression and MAPKs and $\mathrm{I}_{\kappa} \mathrm{B} / \mathrm{k} \mathrm{B}$ kinases/NF-kB pathway in a dose-dependent manner

Attenuated paw swelling and serum cytokine levels

Decreased the expression of inflammatory cytokines and inhibited HIF-1 a/NEGF pathway

Declined the production of inflammatory cytokines and ROS Zhang P et al.

and the expression of TLR2. Prevented p38, ERK, JNK, and (2017) NF-kB phosphorylation

Suppressed NF-KB and MAPK pathway activation by

reducing the upregulation of intercellular adhesion molecule-1 and phosphorylation of NF-kB, p38, ERK1/2, and SAPK/JNK Reduced leukocyte adhesion via inhibiting JNK/P38

phosphorylation, NF-kB activation, and HuR translocation

Suppressed the growth, migration, and invasion of CCA cells

by regulating cell cycle and expression of cyclin D1 protein,

PCNA, Ki67, MMP-2, MMP-7, and MMP-9

Reduced the growth and weight of tumor

Wang et al.

(2012)

Yang et al. (2016)

Wu et al. (2014)

Liang CJ et a

(2014)

Zhang FH et al.

(2017)

Zhang $\mathrm{FH}$ et al.

(2017)

(Continued on following page) 


Effect Model/targets Positive

SKOV3 human ovarian and

BT474 human breast cancer

cells

Human non-small-cell lung

cancer cell lines

Male nude mice

Human HCT116, SW480, and HEK293 cells

Female nude mice

Human gastric

adenocarcinoma SGC-7901

cells

GBC cell lines

BALB/c homozygous nude

mice

Human DU145 and PC3

prostate adenocarcinoma

cells

Human PC3 cells and LNCaP

HCT-116 cells

Human lung carcinoma A549

cells

Nude immunodeficient mice

Human breast cancer cell lines and nontumorigenic MCF

10A mammary epithelial cells

WM1366 (NRAS-mutated)

and WM164 (BRAF-mutated)

cell lines

\section{Dosage}

Result/mechanism/method

In vitro: $6.25,12.5,25$, Inhibited the overexpression of HER2 gene by decreasing Chuang et al.

50, 100, and $200 \mu \rrbracket \quad P \mid 3 K / A k t$ and inhibiting the expression of VEGF, MMP2, and (2011)

cyclin D1

and $20 \mu \mathrm{M} \quad$ cell cycle, destroying cellular microtubule tissue, reducing Akt/

mTOR pathway, and promoting autophagy

In vivo: $25 \mathrm{mg} \mathrm{kg}^{-1} \quad$ Significantly reduced tumor size and weight

(i.p. injection)

In vitro: $12.5,20,25$,

30,50 , and $75 \mu \mathrm{M}$

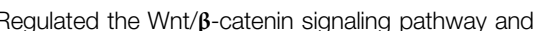

$\beta$-catenin/T-cell factor-targeted downstream genes. Inhibited tumor cell invasion and motility

In vivo: $5 \mathrm{mg} \mathrm{kg}^{-1}$ (i.p. Inhibited the tumor growth effectively with an inhibition rate

injection)

of $54.6 \%$

In vitro: 10, 30, 50, Regulated the mitochondria and PI3K/Akt-dependent

100,200 , and $300 \boldsymbol{\mu M}$ pathways, Bax/Bcl-2 ratio, caspase-3 activation, PI3K/Akt

In vitro: 10,20 ,

inhibition, and cell apoptosis and induced autophagy

and 30 M $\quad$ Altered levels of p53, p21, cyclin D1, CDC25A, and Cak2, related apoptosis

In vivo: 5, 10, 20, 30, Suppressed the tumor growth and CDC2 expression and 40 , and $50 \mathrm{mg} \mathrm{kg}^{-1} \quad$ increased caspase- 3 activation

(i.p. injected)

In vitro: 40 and $80 \mu \mathrm{M} \quad$ Modulated the cell cycle process of PC3 and DU145 cells. Downregulated the expression of A, B1, D1, E, CDK2, CDK4 and pRBp130. And increased pRBp107 protein expression and
level

In vitro: $80 \mu \mathrm{M}$

Affected the expression of insulin-like growth factor-1 (IGF-1), McKeown and and associated proteins including IGF-binding protein-5 (IGFBP-5), IGFBP-3, IGF-1 receptor, and IGFBP-4

In vitro: $1,5,10,25$ and $50 \mu \mathrm{M}$

Promoted cell apoptosis and inhibited migration and invasion of HPT-116 cells by decreasing Bcl-2 expression, increasing the expression of p53 and Bax, and activating AMPK and caspase-3

In vitro: $1,5,10,50$

Upregulted the release of lactate dehydrogenase, faciltated caspase-3 activation and poly-(ADP)-ribose polymerases cleavage, and reduced NF-kB/RelA expression level. Inhibited A549 cells growth

In vitro: $40 \mathrm{mg} \mathrm{kg}^{-1} \quad$ Markedly inhibited the growth of MDA-MB-231 and McF-7 Liu et al. (2013) (i.p. injection) tumors and MMP-9 level

In vitro: 10, 20, 30, 40, Prevented breast cancer cell invasion via inhibiting NF-кB Liu et al. (2013) 50 , and $60 \boldsymbol{\mu M} \quad$ pathway and MMP-9 expression

In vitro: 10,20 ,

and $30 \mu \mathrm{M}$

Park et al. (2012)

Seo et al. (2011)

Emran et al.

(2019)

Continued on following page) 
TABLE 1 | (Continued) Modern pharmacological studies of MG.

Effect Model/targets Positive

PC3 cells

MCF7 cells

Antiangiogenic T24 and HUVEC cells

activity

Female athymic nude mice (BALB/C)

MES/EB-derived endotheliallike cells

HUVEC cells

Male NMRI mice

Cardiovascular Right coronary arteries from protection

hearts of pigs

Human aortic smooth muscle cells (HASMCs)

Male SD rats

Male SD rats

Male SD rats

Male spontaneous

hypertensive rats

VSMCs

Hypoglycemic

3T3-L1 and HIB1 B

activity preadipocytes

\section{Dosage}

\section{Result/mechanism/method}

In vitro: $\mathrm{MG} 80 \mu \mathrm{M}$

In vito: $20 \mu \mathrm{M}$

In vitro: 1,5 ,

and $10 \mu \mathrm{M}$

In vivo: 2,5 , and

$10 \mathrm{mg} \mathrm{kg}^{-1}$ (i.p.

injection)

In vitro: $5,6.25,10$

$12.5,20,25,50$, and

$100 \mu \mathrm{M}$

In vitro: 10 and $40 \mu \mathrm{M}$

In vivo: $20 \mu \mathrm{g} / \mathrm{ear}$

(transdermally

administered)

In vitro: $1,3,10,30$

and $100 \boldsymbol{\mu M}$

In vitro: 10, 20,

and $30 \mu \mathrm{M}$

In vivo: 1,10 , and

$100 \mu \mathrm{kg}^{-1}$

(intravenous (i.v.)

injection)

Ticlopidine $100 \mathrm{mg} \mathrm{kg}^{-1}$ decreased intimal In vivo: 50 and area as well as intimal/medial ratio and increased luminal area

$100 \mathrm{mg} \mathrm{kg}^{-1}$ (gavage)

In vivo:

$10 \mathrm{mg} \mathrm{kg}^{-1}$ (i.p.)

In vivo: $100 \mathrm{mg} \mathrm{kg}^{-1}$

(gavage)

In vitro: 5,10 ,

and $20 \mu \mathrm{M}$

In vitro: $1,5,10$

and $20 \mu \mathrm{M}$
Decreased the protein expression of ornithine decarboxylase R2 subunit of ribonucleotide reductase, $p-p 38$, JNK-1/2,

PI3Kp85, p-PI3Kp85, p-Akt, NFkBp65, p-lkBa, and l/kBa. And increased the protein expressions of $\mathrm{p}-\mathrm{JNK}-1$, and c-Jun Increased the expression of the tumor suppressor miRNA miR-200c

\section{References}

Mckeown and

Hurta (2015)

Hagiwara et al.

(2015)

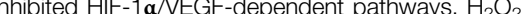

formation, mRNA and protein expression, and transcriptional

and VEGF excretion

Decreased angiogenesis, HIF-1A, VEGF, CD31, and carbonic Chen et al. (2013) anhydrase-IX expression

Inhibited PECAM transcription, translational expression, and Kim GD et al. MAPKs/PI3K/AKT/mTOR signaling pathway activation

Suppressed proliferation, ERK1/2 activity, gelatinase activity, Kuk et al. (2017) and ROS production and promoted HO-1 leve

nhibited venous remodeling process and decreased

endothelial proliferation and MMP-2 abundance. Amplified

HO-1-mediated resistance of endothelial cells to ROS-

mediated proliferative stimul

Relaxed the coronary artery with an $\mathrm{IC}_{50}$ value of $5.78 \mu \mathrm{M}$ and Kuo et al. (2011)

dose-dependently inhibited iNOS and COX-2 protein

expression

Inhibited VSMC migration by suppressing cytoskeleta

remodeling and neontma

Redeling and neointima formation

Reduced the proportion of myocardial ischemic necrosis

area. At a concentration of $10 \mu \mathrm{g} \mathrm{kg}^{-1}$, MG reduced

ventricular fibrillation and animal mortality

Attenuated neointima formation, intimal area, and intimal/ medial ratio and increased luminal area

Karki et al.

(2013a)

Regulated ACE/Ang II/AT-1R cascade and ACE2. Attenuated Chang et al. the overexpressions of ET-1 and ETA receptor by

suppressing Akt/ERK1/2/GSK3ß-catenin pathway

(2018)

Decreased blood pressure through upregulating PPAR- $\gamma$, Liang $X$ et al.

Akt, and eNOS activity, downregulating TRB3, and improving (2014)

vascular insulin resistance

Suppressed VSMC proliferation and DNA synthesis by

inhibiting the expressions of cyclin D1/E, cyclin-dependent

kinase 2 and 4, ROS production, and activation of

renin-angiotensin system, MEK, and ERK $1 / 2$

Enhanced adipocyte differentiation and expression of brown Parray et al.

adipocyte-specific marker genes and proteins. Promoted

browning of 3T3-L1 fat cells via activating AMPK, PPAR, and

PKA pathways 
TABLE 1 | (Continued) Modern pharmacological studies of MG.

Effect Model/targets Positive

Protein tyrosine phosphatase-
1B (PTP1B)

RIN-m5F cells

$\boldsymbol{\alpha}$-Glucosidase

L6 rat myoblast

Insulin-sensitive/resistant

murine and human adipocytes

Gastrointestina

protection

Neuroprotection CMS-induced male Kunming

mice

Castor oil-induced male Kunming mice

ETEC-induced diarrhea male

Kunming mice

Colonic smooth muscle cells from male SD rats

Kunming mice

CMS-induced male ICR mice

Olfactory bulbectomy male ddY mice

Male SD rats subjected to

unpredictable CMS (UCMS)

UCMS-induced male SD rats

Male Kunming strain mice

BV2 cells
Saline $\left(20 \mathrm{mg} \mathrm{kg}^{-1}\right)$ relieved diarrhea

preference

Dosage

In vitro: 5, 10, 20,

and $30 \mu \mathrm{M}$

In vitro: $0.01,0.1$

and $1 \mu \mathrm{M}$

In vitro: $0.5-100 \mu \mathrm{M}$

In vitro: 3,10 ,

and $30 \mu \mathrm{M}$

In vitro: $0.1,1,10$,

and $30 \mu \mathrm{M}$

In vivo: 25, 50, and

$100 \mathrm{mg} \mathrm{kg}^{-1}$ (gavage)

In vivo: 100, 300, and

$500 \mathrm{mg} \mathrm{kg}^{-1}$ (gavage)

In vitro: 1, 3, 10, 30,

and $100 \mu \mathrm{M}$

In vivo: 5, 10, 15, 20,

25,30 , and

$40 \mathrm{mg} \mathrm{kg}^{-1}$ (gavage)

In vivo: 20 and

$40 \mathrm{mg} \mathrm{kg}^{-1}$ (gavage)

Fluoxetine $\left(20 \mathrm{mg} \mathrm{kg}^{-1}\right)$ decreased immobility duration and serum CORT levels

Fluoxetine $\left(20 \mathrm{mg} \mathrm{kg}^{-1}\right)$ ameliorated the depression-like behavior

Fluoxetine hydrochloride $\left(20 \mathrm{mg} \mathrm{kg}^{-1}\right)$ reversed depression-like behavior

Fluoxetine hydrochloride $\left(20 \mathrm{mg} \mathrm{kg}^{-1}\right)$

increased the levels of 5-

hydroxyindoleacetic acid and $5-\mathrm{HT}$

Diazepam $\left(2 \mathrm{mg} \mathrm{kg}^{-1}\right)$ prolonged the latency of epileptic seizures and increased the latency of myoclonic Jerks

vivo: 50 and

$100 \mathrm{mg} \mathrm{kg}^{-1}$ (gavage)

In vivo: 50 and

$100 \mathrm{mg} \mathrm{kg}^{-1}$ (gavage)

In vivo: 20 and

$40 \mathrm{mg} \mathrm{kg}^{-1}$ (gavage)

In vivo: 20 and

$40 \mathrm{mg} \mathrm{kg}^{-1}$ (gavage)

In vivo: 20, 40, and

$80 \mathrm{mg} \mathrm{kg}^{-1}$ (i.p. injection)

In vitro: $2.5,5,10,50$ 100,150 , and $200 \mu \mathrm{M}$

\section{Result/mechanism/method}

value of $24.6 \mu \mathrm{M}$

Increased insulin secretion, Ins2 and PDX1 expression, and Suh et al. (2017)

levels of AMPK phosphorylation, SIRT1, and PGC1a.

Prevented protein glycation

nhibited $\boldsymbol{\alpha}$-glucosidase with an $\mathrm{IC}_{50}$ value of $2.0 \mu \mathrm{M}$ and

$29.8 \%$ inhibition at a concentration of $1.5 \mu \mathrm{M}$

Promoted glucose uptake in a dose-dependent manner and Choi et al. (2012)

stimulated glucose transporter-4 translocation to the cell

surface via enhancing Akt phosphorylation

Promoted glucose uptake by regulating insulin signaling Alonso-Castro

pathway

et al. (2011)

Inhibited diarrhea in mice significantly. Reduced neostigmine- Pang et al. (2013) induced small intestinal transit, and increased activity of CAT, SOD, and GSH-PX

Regulated the release of IP3- $\mathrm{Ca}^{2+}$ storage, suppressed SK Deng et al. (2015)

channel, and facilitated the opening of $B K \boldsymbol{\alpha} 1$ and $B K \beta 3$

channels and the closing of BK $\boldsymbol{B} 4$ channel

Downregulated L-type $\mathrm{Ca}^{2+}$ channel activity to inhibit the spontaneous contractions of colonic smooth muscle occur in a concentration-dependent manner

It had significant inhibitory effects on the small intestine

charcoal propulsion induced by rhubarb, diarrhea induced by

Senna leaf, and gastric emptying inhibition induced by

atropine

Inhibited prefrontal cortex oxidative stress and depression-

like behavior by reducing the levels of IL-1 $\boldsymbol{\beta}, \mathrm{LL}-6$, and TNF- $\boldsymbol{\alpha}$,

microglia cell activation, HPA axis hyperactivity and lipid

peroxidation, and increasing enzymes decrease

Modulated HPA axis and upregulated BDNF protein, 5-HT, Bai et al. (2018)

and norepinephrine (NE) level. Decreased CORT leve

Ameliorated depression-like behavior and hippocampal nerve

Matsui et al. (2016) injury significantly

Ameliorated depression-like behaviors via reversing glial _ L LF et al. (2013)

atrophy

Increased BDNF expression and serotonergic system activity Li et al. (2012)

Delayed myoclonic jerks and myoclonic seizures. Declined Chen CR et al. (2011) seizure stage and mortality by affecting GABAA

benzodiazepine receptor

ncreased A $\boldsymbol{\beta}$ phagocytosis and degradation and ApoE level Xie et al. (2020) by activating the target gene liver-X-receptor of PPAR- $\gamma$

(Continued on following page) 
TABLE 1 | (Continued) Modern pharmacological studies of MG.

Effect Model/targets Positive

Male SD rats

TMT-induced HT22 cells and BV-2 cells

TMT-induced male ICR mice

Glutamate-induced neurons

Male SD rats

Stroke male SD rats

LPS-induced microglial cells, brain microvascular

endothelial cells

I-R-induced Kunming mice

Fluid percussion-induced

male SD rats

Neuronal NG108-15 cells

Interaction with

CYP450 enzyme

Male SD rats

Rat/human CYP enzymes

(1A2/1A2, 2D/2D6, 3A/3A4

$2 \mathrm{E} 1 / 2 \mathrm{E} 1$, and $2 \mathrm{C} / 2 \mathrm{C} 9$ )

Human CYP2C19

SD rat CYP2D

CYP2C, CYP2D6, CYP2E1,

CYP3A4, CYP1A2, and

CYP2B6

Male SD rats

CYP1A2, CYP2B6, CYP2C8,

CYP2C9, CYP2C19,

CYP2D6, and CYP3A
In vivo: $30 \mathrm{mg} \mathrm{kg}^{-1}$ (i.p.

injection)

In vitro: 5, 10, 15 and $20 \mu \mathrm{M}$

In vivo: $25 \mathrm{mg} \mathrm{kg}^{-1}$ (i.p. injection)

In vitro: $0.1,1 \mu \mathrm{M}$

In vivo: 25, 50, 100, 150 and $200 \mathrm{mg} \mathrm{kg}^{-1}$ (i.p.)

In vivo: 10 and

$30 \mathrm{mg} \mathrm{kg}^{-1}$ (i.p. injection)

In vitro: $0.01,0.1,1$

and $10 \mu \mathrm{M}$

Edaravone $\left(3 \mathrm{mg} \mathrm{kg}^{-1}\right)$ reduced about $33 \%$ of the white infarct areas and failed to inhibit Evans blue secretion and brain edema

In vivo: $1.4,7.0$, and

Attenuated brain water content and neurological deficits and restored the BBB by reducing glial cell stimulation, neutrophil

infiltration, and production of IL-1 $\boldsymbol{\beta}$, TNF- $\boldsymbol{\alpha}$, and MMP-9

Inhibited neuronal cell death and microglial activation by

suppressing ROS production and activation of JNK, p38 MAPKs, and NF-kB

Reversed a large number of neuronal injury and oxidative stress induced by TMT. Decreased glial cells and INOS expression and blocked the activation of JNK and P38

Attenuated intracellular $\mathrm{Ca}^{2+}$ levels, $\left[\mathrm{Ca}^{2+}\right]$ increase, cytotoxicity, and cell swelling

The infarct area was significantly reduced by $30.9-37.8 \%$, and neurobehavioral scores were improved

Deduced the levels of IL-1 $\boldsymbol{\beta}, \mathrm{IL}-6$, and TNF- $\boldsymbol{\alpha}$. Inhibited the production of 4-HNE, iNOS, nitrotyrosine, C/EBP homologs, and phosphorylated p38MAPKs

Attenuated the BBB hyperpermeability in a dose- and timedependent manner. Reduced levels of iNOS, TNF- $\boldsymbol{\alpha}$, and IL-

$1 \beta$ and p65 subunit expression

Reduced infarct volume, cerebral water content, and Evans $35.0 \mu \mathrm{g} \mathrm{kg}^{-1}$ (i.v. injection) blue secretion

In vivo: 0.2 and $2 \mathrm{mg} \mathrm{kg}^{-1}$ (i.v. injection)

In vitro: 10, 30, and

$100 \mu \mathrm{M}$

In vivo: $50 \mathrm{mg} \mathrm{kg}^{-1}$

(gavage)

In vitro: $8,10,16,32$

and $64 \mu \mathrm{M}$

The $\mathrm{IC}_{50}$ value of $1.37 \mu \mathrm{M}$ for loratadine $\quad$ In vitro: $0.1,0.25,0.5$,

$0.75,1,1.5$, and $2 \mu \mathrm{M}$

In vitro: $3.91-125 \mu \mathrm{M}$

In vitro

In vivo: $5 \mathrm{mg} \mathrm{kg}^{-1}$

In vitro: $0.5-50 \mu \mathrm{M}$ and CYP2A1/2 and human CYP2E1 and CYP2A6 with IC 50
Reduced cerebral infarction volume and neuronal apoptosis. Increased the expression of transforming growth factor $\boldsymbol{\beta} \boldsymbol{\beta}$ hhibited the voltage $\mathrm{K}^{+}$and voltage-gated $\mathrm{Na}^{+}$channels with IC50 values of 21 and $15-30 \mu \mathrm{M}$

Inhibited CYP1A and 2C significantly

Inhibited human $\mathrm{CYP}_{3} \mathrm{~A}_{4}$ and rat CYP1A2 with $1 \mathrm{C}_{50}$ values of 56.2 and $10 \mu \mathrm{M}$, respectively

Noncompetitive inhibition of CYP2C19 with $\mathrm{IC}_{50}$ and Ki values of $1.37 \mu \rrbracket$ and $10.0 \mu \mathrm{M}$, respectively

Inhibited the CYP2D in a dose-dependent manner, with an $\mathrm{IC}_{50}$ value of $39.9 \mu \mathrm{M}$. And inhibited rat CYP2C8, CYP2E1, values $>100 \mu \mathrm{M}$

The $\mathrm{IC}_{50}$ values of MG on rat CYP2C, CYP2D6, CYP2E1, CYP3A4, CYP1A2, and CYP2B6, were $5.56 \pm 2.87 \mu \mathrm{M}$,

$65.42 \pm 4.46,67.93 \pm 9.51,52.36 \pm 17.32,97.80 \pm 3.83$, and $28.69 \pm 1.46$, respectively

The mean $\mathrm{IC}_{50}$ values of $\mathrm{MG}$ for the metabolism of phenacetin Kim SB et al. and diclofenac were 19.0 and $47.3 \mu \mathrm{M}$, respectively

The IC ${ }_{50}$ values for the CYP1A2, CYP2B6, and CYP2C9 were Joo and Liu $5.4,44.9$, and 10.2, respectively (2018)

Kim and Kim (2016)

Lee et al. (2012)

Lee et al. (2012)

Chen et al. (2014)

Liu et al. (2017)

Wang CC et al. (2013)

Gong et al. (2012)

Duan et al. (2015)

Duan et al. (2015)

Zhang $T$ et a

2018)

u et al. (2016)

Huang et al.

2019

(2013) 
TABLE 1 | (Continued) Modern pharmacological studies of MG.

Effect Model/targets Positive

\section{Dosage}

In vitro: 2, 4, 6, 8, and

$16 \mu \mathrm{ml}^{-1}$

In vitro: 8-128 $\mathrm{mg} \mathrm{L}^{-1}$

MRSA, MSSA, and ATCC

25923

64 Candida spp. strains

32 Fusarium spp. strains

A. actinomycetemcomitans, S. mutans, S. aureus, MRSA, and E. coli

Alternaria alternata (Fr.) Keiss

Penicillium expansum (Link)

Thom, Alternaria dauci f.sp.

solani, Fusarium moniliforme

J. Sheld, Fusarium oxysporum

Schltdl., Valsa mali Miyabe \&

G. Yamada, and Rhizoctonia

solani J.G. Kühn A

Antioxidative activity Acrolein-induced SH-SY5Y

human neuroblastoma cells

AA-induced HK-2 cells

Male $\mathrm{C} 3 \mathrm{H} / \mathrm{HeOuJ}$ mice

Antiphotoaging

UVB-induced HR-1 hairless

activity male mice

\section{Inhibition of \\ RAW 264.7 macrophages}

osteoclast

differentiation

DSCs

Male SD rats

MC3T3-E1 cells

RANKL-induced RAW

264.7 macrophages

Male SD rats

Amphotericin B (the range of MIC value In vitro: $0.5-256 \mu \mathrm{g} \mathrm{ml}^{-1}$ was $0.12-0.5 \mathrm{\mu g} \mathrm{ml}^{-1}$ )

In vitro: $5-400 \mu \mathrm{g} \mathrm{ml^{-1 }}$

Cycloheximide, the MIC/MBC values of In vitro: $1-100 \mu \mathrm{g} \mathrm{ml}^{-1}$ $<1 /<1,<1 /<1,1</ 2,1</<1$, and $1</$ $<1 \mu \mathrm{g} \mathrm{ml}^{-1}$

In vitro: $0.001,0.005$

$0.01,1,3,5$, and

$7 \mathrm{mg} \mathrm{ml}^{-1}$

In vitro: 5 and $10 \mu \mathrm{M}$

Hypertonic saline (4 ml kg-1 7.5\%) reduced interstitial edema and blood DHR 123 oxidation

vivo: $20 \mathrm{mg} \mathrm{g}^{-1}$ (i.v. injection)

In vitro: $40 \mu \mathrm{L}$ of the formulation containing $0.25 \% \mathrm{MG}$ (topically

applied)

In vitro: $2.5,5,10$, and $20 \mu \mathrm{M}$ In vivo: $20 \mathrm{mg} \mathrm{kg}^{-1}$ (i.p. injection)

In vitro: $0.01,0.1$ and $1 \mu \mathrm{M}$

In vitro: 75,100 , and

$150 \mu \mathrm{M}$

\section{Result/mechanism/metho}

The MIC values ranged from 32-64 $\mu \mathrm{g} \mathrm{ml}^{-1}$

The MIC50/MBC50 values of MSSA and MRSA were 32/32 and 16/16 $\mathrm{mg} \mathrm{L}^{-1}$, respectively

In vitro: 8,16 , and $32 \mu$ prolonging the vitality in acrolein-induced $\mathrm{SH}-\mathrm{SY} 5 \mathrm{Y}$ cells by altering JNK/mitochondria/caspase, PI3K/MEK/ERK/Akt/O subfamily of FoxO 1 signaling pathways

In vitro: 5,10 , or $20 \mu \mathrm{M}$

In vivo: $100 \mathrm{mg} \mathrm{kg}^{-1}$ (р.o.) MMP-1, MMP-9, and MMP-13
Effectively reduced oxidative stress, suppressed cell

proliferation, and prevented the G2/M arrest induced by AA. Attenuated lung injury by significantly reducing pulmonary edema, iNOS expression, MPO activity, and plasma

peroxynitrite

Reduced the mean length and depth of wrinkles and levels of Im et al. (2015)

Suppressed MAPK/c-fos/AP-1/NF-kB signaling and ROS production. Increased $\mathrm{HO}-1$ expression

Inhibited ALP activity and calcium deposits

Suppressed the expressions of RUNX2, OCN, and BMP2

Significantly downregulated the production of osteoclast differentiation-inducing factors such as RANKL, TNF-a, and L-6 and inhibited mitochondrial electron transport

Decreased osteoclast differentiation, tartrate-resistant acid phosphatase activity of differentiated cells, and resorption pit area caused by osteoclasts in a concentration-dependent manner

Significantly suppressed alveolar bone resorption, the number of osteoclasts on the bony surface, expression of RANKL, MMP-1, MMP-9, iNOS and COX-2, and TNF- $\boldsymbol{\alpha}$ activation

\section{References}

Dong et al. (2017)

Zuo et al. (2015)

Behbehani et al (2017) Oufensou et al.

2019)

Chiu et al. (2020)

Chen $\mathrm{Y}-\mathrm{H}$ et al. (2019)

Dong et al. (2013)

Bunel et al. (2016) Shih et al. (2012)

Lu et al. (2015a)

Zhou W et al.

(2019)

Kwak et al. (2012)

Lu et al. (2013)

Lu et al. (2013)

ontinued on following page) 

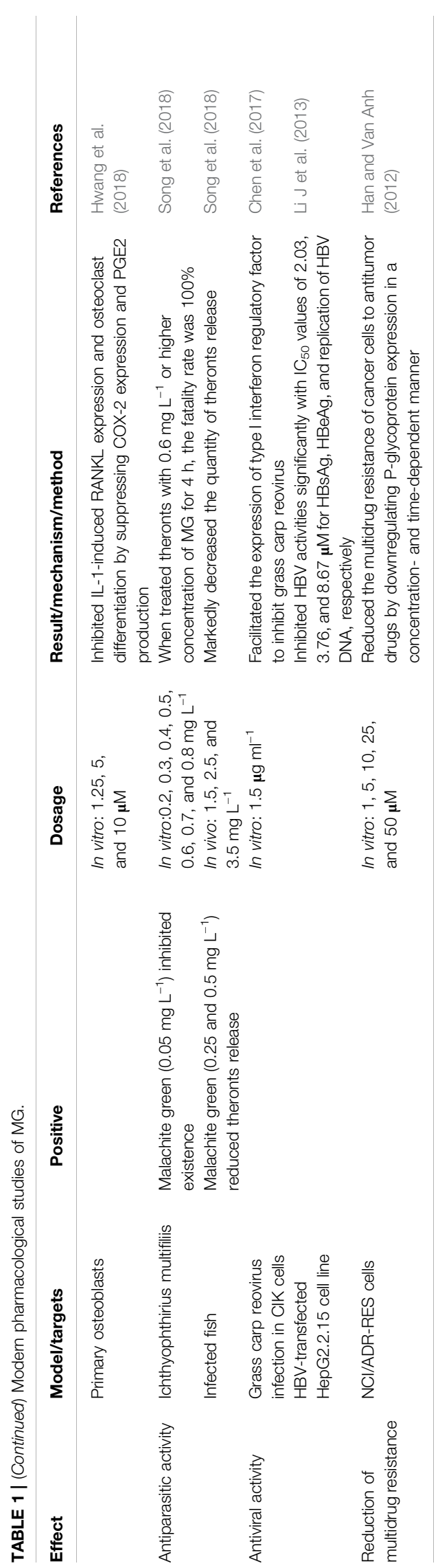

(COX-2) and excessive synthesis of nitric oxide (NO) and prostaglandins (PGEs) (Chen $\mathrm{H}$ et al., 2019). Mitogenactivated protein kinase (MAPK) and nuclear factor- $\mathrm{kB}$ (NF$\kappa B)$ are the most crucial signaling pathways in the inflammatory process. MAPK includes four subfamilies: extracellular signalregulated kinase (ERK), stress-activated protein kinase (SAPK)/ c-Jun $\mathrm{N}$-terminal kinase (JNK), big mitogen-activated protein kinase 1 (BMK1)/ERK5, and p38MAPK, which participates in cell growth, differentiation, apoptosis, immune regulation, etc. Furthermore, NF- $\mathrm{kB}$ consists of isotype or heteromorphic p50 and p65 protein, which affects the expression of inflammatory and growth factors, chemokines, COX-2, and iNOS involved in the processes of inflammation, apoptosis, tumorigenesis, etc. (Lu et al., 2015b). MG exhibited anti-inflammatory activity by inhibiting Toll-like receptor2 (TLR2)/TLR4/NF- $\mathrm{kB} / \mathrm{MAPK} /$ peroxisome proliferator-activated receptor- $\gamma$ (PPAR- $\gamma$ ) pathways and downregulating the expression of inflammatory cytokines (Luo et al., 2013; Wang et al., 2014; Wei et al., 2014; Lin et al., 2015; Lu et al., 2015a; Yang et al., 2016; Zhang L et al., 2018; Chen H et al., 2019; Piasecka et al., 2020).

MG $(5-15 \mu \mathrm{M})$ could exhibit anti-inflammatory activity in lipopolysaccharide (LPS)-induced RAW 264.7 cells. It decreased the translocation of p50 and p65 subunits and downstream NF- $\mathrm{KB}$ transcription through downregulating inhibitor kappa B (I B) degradation and phosphorylation. Additionally, MG blocked the phosphorylation of ERK1/2, JNK1/2, and phosphatidylinositol 3-kinase (PI3K)/protein kinase B (Akt) signal, interfered with the activation of PI3K/ Akt, MAPK, and NF-kB pathway, and thus inhibited iNOS and COX-2 protein and gene expression (Lai et al., 2011). MG $(5-20 \mu \mathrm{M})$ significantly suppressed inflammatory reaction, production of pro-inflammatory cytokines, PGE2, and nitrite, expression of iNOS and COX-2, and activation of NF-kB. Meanwhile, it elevated nuclear factor-erythroid 2related factor 2 (Nrf2) nuclear translocation and heme oxygenase (HO)-1 expression (Lu et al., 2015b).

MG (20 mg kg${ }^{-1}$, intraperitoneal (i.p.) injection) played roles in significantly ameliorating pathological characteristics and inhibiting the inflammatory reaction of acute lung injury in male Sprague Dawley (SD) rats. It could attenuate pneumonic edema, neutrophil infiltration, reactive oxygen species (ROS) production, $\mathrm{iNOS}$ and COX-2 expression, and NF- $\mathrm{\kappa B}$ activation and upregulate PPAR- $\gamma$ expression (Lin et al., 2015). MG $\left(25 \mathrm{mg} \mathrm{kg}^{-1}\right.$, i.p.) exhibited therapeutic effect for pathological retinal angiogenesis and glial dysfunctions by decreasing the expression of inflammatory cytokines and inactivating the HIF1a/VEGF pathway (Yang et al., 2016).

The above results showed that MG has the effect of treating inflammation. However, most of the studies lacked positive groups. Positive groups should be set in follow-up studies.

\section{Antitumor Activity}

In the past few decades, in order to elucidate the molecular mechanisms of tumor formation and tumorigenesis and explore therapeutic methods, a mass of studies have been done. Currently, commonly used treatment methods include 
radiotherapy, chemotherapy, and surgery. However, present chemotherapeutic drugs have adverse reactions such as vomiting, hair loss, kidney damage, and bone marrow destruction. It is an important challenge to find effective and economic antitumor drugs with minimum side effects. A large number of literature studies have shown that MG has antitumor activity against colon cancer (Kang et al., 2012; Park et al., 2012), prostate cancer (McKeown et al., 2014), liver cancer, lung cancer (Seo et al., 2011; Shen et al., 2017), gastric cancer (Rasul et al., 2012), cholangiocarcinoma (Zhang FH et al., 2017), oral cancer (Hsieh et al., 2018), ovarian cancer (Chuang et al., 2011), breast cancer (Liu et al., 2013), and melanoma (Cheng et al., 2020). MG suppressed the growth, migration, and invasion of tumor cells and promoted apoptosis as well as autophagy by acting on caspase- 8 , caspase- 3 , and other proteins participated in the p53, MAPK, NF- $\kappa$ B, TLR, HIF-1 $\alpha /$ VEGF, PI3K/Akt/ERK/ mammalian target of rapamycin (mTOR), and $\mathrm{Wnt} / \beta$-catenin signaling pathways (Chen et al., 2013; Liu et al., 2013; Li et al., 2015; Shen et al., 2017; Zhang P et al., 2017).

In vitro, $\mathrm{MG}(80 \mu \mathrm{M})$ showed the activity of suppressing the proliferation of PC3 cells (McKeown and Hurta, 2015). It could decrease the protein expression of ornithine decarboxylase, R2 subunit of ribonucleotide reductase, p-p38, JNK-1/2, PI3Kp85,

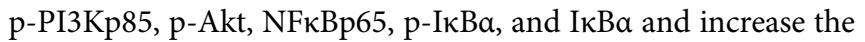
expression of p-JNK-1 and c-Jun. MG (10-30 $\mu \mathrm{M})$ inhibited $\mathrm{BRAF} /$ mitogen-activated protein kinase (MEK) and induced cell death in melanoma via significantly downregulating PI3K/ Akt pathway, which brought about a reduction of the active histone mark H3K4me3. The combination of MG and BRAF/ MEK inhibitors dabrafenib/trametinib or docetaxel could have a synergistic effect (Emran et al., 2019). In MCF-7 cells, MG $(20 \mu \mathrm{M})$ increased the expression of the tumor suppressor miRNA miR-200c to inhibit zinc finger E-box-binding homeobox 1 and increased the expression of E-cadherin (Hagiwara et al., 2015; Biersack, 2018). MG (40 $\mu \mathrm{M})$ regulated the NF- $\kappa \mathrm{B}$ pathway, induced cell cycle arrest, downregulated cyclin D1, and inhibited the expression of proliferating cell nuclear antigen (PCNA), Ki67, matrix metalloproteinase (MMP)-2, MMP-7, and MMP-9 to control the growth, migration, and invasion of QBC939 cells (Zhang FH et al., 2017). In A549 cells, MG (1-50 $\mu \mathrm{M})$ showed growth inhibition and autophagy via activating caspase- 3 and poly-(ADP)-ribose polymerase cleavage, reducing NF- $\kappa \mathrm{B} /$ Rel $\mathrm{A}$ and Akt/mTOR pathway expression, dose-dependently blocking mitosis and G2/M progression, and increasing the release of lactate dehydrogenase (Liu et al., 2013; Shen et al., 2017). What is more, in OC2 cells, MG $(20-100 \mu \mathrm{M})$ played roles of $[\mathrm{Ca} 2+]$ increase, phospholipase $\mathrm{C}$-dependent $\mathrm{Ca} 2+$ release from the endoplasmic reticulum, $\mathrm{Ca} 2+$ entry, and $\mathrm{Ca} 2+$-independent cell death (Hsieh et al., 2018). In U87MG and LN229 human glioma cells, cotreatment with $\mathrm{MG}$ and honokiol exerted a synergistic antitumor effect to induce cell cycle arrest as well as autophagy and inhibit proliferation by decreasing cyclin A/D1, cyclin-dependent kinase 2, 4, 6, p-PI3K, p-Akt, Ki67, p-p38, and p-JNK and elevating p-ERK expression (Cheng et al., 2016).

In vivo, $\mathrm{MG}$ (5-20 $\mathrm{mg} \mathrm{kg}^{-1}$, i.p. injection) inhibited the growth of $\mathrm{GBC}-\mathrm{SD}$ tumor in $\mathrm{BALB} / \mathrm{c}$ nude xenograft model. It significantly increased caspase- 3 activation and inhibited cell division cycle gene (CDC) 2 expression ( $\mathrm{Li}$ et al., 2015). In addition, treated with $\mathrm{MG}$ (40 $\mathrm{mg} \mathrm{kg}^{-1}$, i.p. injection) in the nude immune-deficient mice, it could be observed that the growth of nude immune-deficient MDA-MB-231 and MCF-7 tumors was inhibited, and the level of MMP-9 was decreased (Liu et al., 2013). In the human GBM orthotopic xenograft model, compared with temozolomide, cotreatment with $\mathrm{MG}$ and honokiol could more effectively inhibit tumor progression and induce apoptosis (Cheng et al., 2016).

In a word, MG and honokiol suppress the proliferation, migration, and invasion of tumor cells and promote apoptosis as well as autophagy by regulating MAPK, NF- $\kappa \mathrm{B}, \mathrm{HIF}-\alpha, \mathrm{PI} 3 \mathrm{~K} /$ $\mathrm{Akt} / \mathrm{ERK} / \mathrm{mTOR}$, and $\mathrm{Wnt} / \beta$-catenin signaling pathways (Tse et al., 2005; Vavilala et al., 2014; Lin et al., 2016; Lee et al., 2019). In addition, MG shows antitumor activity by regulating TLR signaling pathways. Honokiol also can regulate STAF, EGFR, and notch signaling pathways to exhibit antitumor activities (Leeman-Neill et al., 2010; Liu et al., 2012; Kaushik et al., 2015). Further experiments in vivo are needed, and attention should be paid to whether MG could cause side effects.

\section{Antiangiogenesis Activity}

Angiogenesis, the essential procedure of embryonic angiogenesis, organ regeneration, and wound healing, is involved in many pathological illnesses, such as cancer, rheumatoid arthritis, and diabetic retinopathy. It is of great significance to study the molecular mechanism of angiogenesis, find relevant new drugs, and provide potential lead candidates. Studies have shown that ROS can participate in the signal transduction cascade in the key steps of angiogenesis and regulate the growth and migration of endothelial cells. MG inhibited angiogenesis through regulating the $\mathrm{PI} 3 \mathrm{~K} / \mathrm{Akt} / \mathrm{mTOR}$ signaling pathway and HIF-1 $\alpha$ /vascular endothelial growth factor (VEGF)dependent pathway and inhibiting ROS production (Kim GD et al., 2013; Chen et al., 2013).

MG $(10 \mu \mathrm{M})$ reduced the accumulation of HIF-1 1 p protein by enhancing the activity of prolyl hydroxylase and reducing the synthesis of HIF-1a protein (Chen et al., 2013). MG $(20 \mu \mathrm{M})$ has been shown to significantly inhibit the transcription and translation activity of platelet endothelial cell adhesion molecules and induce the production of ROS by mediating mitochondria and apoptosis. Furthermore, MG inhibited the activation of MAPKs and PI3K/Akt/mTOR signaling pathways in mouse embryonic stem (MES)/embryoid body (EB)-derived endothelial-like cells (Kim GD et al., 2013). MG (10 and $40 \mu \mathrm{M})$ suppressed the proliferation of human umbilical vein endothelial cells (HUVECs), ERK1/2 activity, gelatinase activity, and production of ROS and promoted HO-1 levels (Kuk et al., 2017).

In the T24 xenograft mouse (C57BL/6 mice), MG (5-10 $\mathrm{mg} \mathrm{kg}^{-1}$, i.p. injection) inhibited angiogenesis, tumor proliferation, and the expression of HIF-1 $\alpha$, VEGF, endothelial cell marker CD31, and endogenous hypoxia biomarker carbonic anhydrase IX by suppressing HIF-1 $\alpha$ /VEGF-dependent pathway (Chen et al., 2013). MG $(20 \mu \mathrm{g} /$ ear $)$ was transdermally administered to male NMRI mice. It inhibited the venous remodeling process and decreased endothelial proliferation 
and MMP-2 abundance by amplifying the HO-1-mediated resistance of endothelial cells to ROS-mediated proliferative stimuli and blocking the proteolytic activity upon biomechanical load (Kuk et al., 2017).

\section{Cardiovascular Protection}

Cardiovascular disease is a large class of diseases, including coronary artery disease, hypertension, dyslipidemia, congenital heart disease, valve disease, and arrhythmia. With the improvement of people's living standards, the incidence of cardiovascular diseases is gradually increasing. MG showed activities of inhibiting the migration and hyperplasia of vascular smooth muscle cells (VSMCs), such as antiplatelet, antithrombotic, and antihypertensive via inhibiting MAPK family activation, Akt/ERK1/2/GSK3 $\beta$-catenin pathway, and angiotensin-converting enzyme (ACE)/angiotensin II (Ang II)/ Ang II type 1 receptor (AT-1R) cascade and upregulating PPAR$\beta / \gamma$ and $\mathrm{NO} /$ guanosine $3^{\prime}, 5^{\prime}$-cyclic phosphate/PKG pathways (Shih and Chou, 2012; Karki et al., 2013b; Liang X et al., 2014; Wu et al., 2015; Chang et al., 2018).

Under pathological conditions, the proliferation and migration of VSMCs to the intima can lead to vascular diseases such as atherosclerosis and restenosis after balloon angioplasty (Karki et al., 2012). MG (20 and $30 \mu \mathrm{M})$ inhibited VSMCs migration, $\beta 1$-integrin expression, focal adhesion kinase (FAK) phosphorylation, RhoA and cell division cycle 42 (Cdc42) activation, and collagen-induced stress fiber formation (Karki et al., 2013b). MG (20 $\mu \mathrm{M})$ suppressed VSMC proliferation and DNA synthesis by inhibiting the expression of cyclin D1/E and cyclin-dependent kinase 2 and 4, ROS production, and activation of renin-angiotensin system, MEK, and ERK1/2 (Karki et al., 2013a; Wu et al., 2015). Additionally, it (1-100 $\mu \mathrm{M})$ could play the role of vasodilator and eliminate superoxide anion by relaxing right coronary arteries (separated from hearts of pigs) in a dosedependent manner and controlling the expression levels of iNOS and COX-2, with an $\mathrm{IC}_{50}$ value of $5.78 \mu \mathrm{M}$ (Kuo et al., 2011). Further pharmacological research in this field was needed to reveal the mechanism by which MG inhibited homocysteineinduced endothelium-dependent vasodilation damage.

In vivo, MG (50 and $100 \mathrm{mg} \mathrm{kg}^{-1}$, gavage) caused attenuation of neointima formation, intimal area, and intimal/medial ratio and increase of luminal area via significantly decreasing the expression of cyclin D1/E and CDK4/2 mRNA and protein (Karki et al., 2013a). In male SD rats with pulmonary hypertension (PHA), MG (100 $\mathrm{mg} \mathrm{kg}^{-1}$, i.p. injection) exerted a therapeutic effect of PHA by altering the Akt/ERK1/2/glycogen synthase kinase $3 \beta$ (GSK3 $\beta$ )-catenin pathway. It upregulated ACE2 and significantly downregulated the expression of iNOS, endothelin-1 (ET-1), and ETA receptors and $\mathrm{O}^{2-}$ production (Chang et al., 2018).

\section{Hypoglycemic Activity}

Diabetes is a metabolic disease characterized by hyperglycemia, which is caused by insufficient insulin excretion and impaired biological effects. Long-term hyperglycemia can contribute to chronic injury and dysfunction in numerous tissues, especially eyes, kidneys, and heart. Type 2 diabetes, formerly known as adult-onset diabetes, mostly occurs after 35-40 years of age and accounts for more than $90 \%$ of diabetic patients (Maddaloni et al., 2020). Numerous studies have reported that MG exhibits the hypoglycemic activity and protein tyrosine phosphatase $1 \mathrm{~B}$ (PTP1B) inhibition by mediating AMPK/silent information regulator 1 (SIRT1)/PGC-1 $\alpha$, PPAR- $\gamma$, and protein kinase A (PKA) pathways, enhancing the activities of glyoxalase 1, PDX1, Ins2, and GPX genes, stimulating Akt phosphorylation, and inhibiting a-glucosidase (Choi et al., 2012; Wang HY et al., 2013; Onoda et al., 2016; Pulvirenti et al., 2017; Suh et al., 2017; Parray et al., 2018).

Low-dose MG (0.01-1 $\mu \mathrm{M})$ inhibited the death of RIN-m5F cells and the decrease of insulin secretion induced by methylglyoxal, thereby exerting hypoglycemic activity (Suh et al., 2017). It could upregulate the expression of Ins2 and PDX1, the levels of SIRT1 and PGC1a, AMPK phosphorylation, and glyoxalase 1 activity. Moreover, it attenuated the level of methylglyoxal-modified protein adducts and protected protein glycosylation (Alonso-Castro et al., 2011). In L6 myotubes, honokiol $(3-30 \mu \mathrm{M})$ and $\mathrm{MG}(3-30 \mu \mathrm{M})$ stimulated glucose uptake in a dose-dependent manner and promoted the translocation of glucose transporter- 4 to the cell surface as well as Akt phosphorylation. Their activity to stimulate glucose uptake could be blocked by the phosphatidylinositol 3kinase inhibitor, wortmannin (Choi et al., 2012). MG $(20 \mu \mathrm{M})$ reduced metabolic disorders, oxidative stress, and fat formation by promoting the adipocyte differentiation and browning of 3T3L1 C3H10T1/2 cells adipocyte-specific marker genes (uncoupling protein 1, CD137, Tbx1, etc.) and protein expression (Parray et al., 2018). It upregulated key fatty acid oxidation and lipid biomarkers (carnitine palmitoyltransferase 1C, acyl-CoA synthase long-chain family member 1, SIRT1, and perilipin) and activated AMPK, PPAR- $\gamma$, and PKA pathways. Honokiol and $\mathrm{MG}$ inhibited a-glucosidase with $\mathrm{IC}_{50}$ values of 2.3 and $0.4 \mu \mathrm{M}$, respectively (Wang $\mathrm{HY}$ et al., 2013). Moreover, their inhibition at $1.5 \mu \mathrm{M}$ was 3.9 and $29.8 \%$, respectively (Pulvirenti et al., 2017). The inhibitory effect of honokiol on a-glucosidase was lower than that of MG.

C57BL/6J mice were fed a high-fat diet ( $45 \mathrm{kcal} \%$ fat) with or without honokiol $(0.02 \%$, w/w) or MG $(0.02 \%$, w/w) for 16 weeks. The results showed that honokiol and MG significantly lowered the weight of white adipose tissue, adipocyte size, and proinflammatory gene expression, protected against insulin resistance, and elevated plasma IL-10 level. In particular, honokiol could significantly decrease the plasma resistin level and increase the plasma adiponectin level compared to the control group (Kim YJ et al., 2013).

It can be seen that MG and honokiol have similar mechanisms to play a hypoglycemic role, such as inhibition of a-glucosidase and stimulation of glucose uptake. The difference is that MG has a better inhibitory effect on $\alpha$-glucosidase, while honokiol can significantly decrease the plasma resistin level and increase the plasma adiponectin level.

\section{Gastrointestinal Protection}

In vitro, $\mathrm{MG}(3-100 \mu \mathrm{M})$ inhibited the spontaneous contraction, acetylcholine (ACh)- and Bay k8664-induced contraction, L-type 
TABLE 2 | Toxicity of MG.

\begin{tabular}{|c|c|c|c|c|}
\hline Activity & Cell lines & Dosage & Application & References \\
\hline $\begin{array}{l}\text { Inhibition of cell } \\
\text { viability }\end{array}$ & U937 and LO-2 cells & $10-100 \mu \mathrm{M}$ & In vitro & Chen $\mathrm{H}$ et al. (2019) \\
\hline $\begin{array}{l}\text { Inhibition of cell } \\
\text { viability }\end{array}$ & MMECs & 50-200 $\mu \mathrm{g} \mathrm{ml}^{-1}$ & In vitro & Wei et al. (2014) \\
\hline $\begin{array}{l}\text { Inhibition of cell } \\
\text { migration }\end{array}$ & VSMCs & $40 \mu \mathrm{M}$ & In vitro & Karki et al. (2013a) \\
\hline $\begin{array}{l}\text { Inhibition of cell } \\
\text { viability }\end{array}$ & $\begin{array}{l}\text { Murine 3T3-F442A predipocytes and human } \\
\text { normal subcutaneous predipocytes }\end{array}$ & $30-100 \mu \mathrm{M}$ & In vitro & $\begin{array}{l}\text { Alonso-Castro et al. } \\
(2011)\end{array}$ \\
\hline $\begin{array}{l}\text { Inhibition of cell } \\
\text { growth }\end{array}$ & mES-derived endothelial-like cells & $50-100 \mu \mathrm{M}$ & In vitro & Kim GD et al. (2013) \\
\hline $\begin{array}{l}\text { Inhibition of cell } \\
\text { viability }\end{array}$ & $\begin{array}{l}\text { MCF-10A, MCF-7, SK-BR3, MDA-MB-453, MDA- } \\
\text { MB-435S, MDA-MB-231, and MDA-MB-468 cells }\end{array}$ & $\begin{array}{c}I_{50}: 70.52 \pm 5.09,36.46 \pm 2.38,59.40 \pm 8.24,35.69 \pm \\
4.91,25.39 \pm 3.26,25.32 \pm 2.72, \text { and } 24.79 \pm 3.06 \mu \mathrm{M} \\
\text { respectively }\end{array}$ & In vitro & Liu et al. (2013) \\
\hline $\begin{array}{l}\text { Inhibition of cell } \\
\text { viability }\end{array}$ & HCT-116 cells & $1-50 \mu \mathrm{M}$ & In vitro & Park et al. (2012) \\
\hline $\begin{array}{l}\text { Inhibition of cell } \\
\text { viability }\end{array}$ & OC2 cells & $20-100 \mu \mathrm{M}$ & In vitro & Hsieh et al. (2018) \\
\hline $\begin{array}{l}\text { Inhibition of cell } \\
\text { viability }\end{array}$ & A549 cells & $6.25-200 \mu \mathrm{M}$ & In vitro & Wu et al. (2014) \\
\hline $\begin{array}{l}\text { Inhibition of cell } \\
\text { viability }\end{array}$ & DU145 and PC3 cells & 40 and $80 \mu \mathrm{M}$ & In vitro & $\begin{array}{l}\text { Mckeown et al. } \\
(2014)\end{array}$ \\
\hline $\begin{array}{l}\text { Induction of cell } \\
\text { apoptosis }\end{array}$ & GBC cells & $10-30 \mu \mathrm{M}$ & In vitro & Li et al. (2015) \\
\hline $\begin{array}{l}\text { Induction of cell } \\
\text { apoptosis }\end{array}$ & SGC-7901 cells & $10-300 \mu \mathrm{M}$ & In vitro & Rasul et al. (2012) \\
\hline $\begin{array}{l}\text { Inhibition of cell } \\
\text { proliferation }\end{array}$ & SKOV3 and TOV21G cells & $6.25-100 \mu \mathrm{M}$ & In vitro & Chuang et al. (2011) \\
\hline $\begin{array}{l}\text { Inhibition of cell } \\
\text { proliferation }\end{array}$ & QBC939, SK-ChA-1, MZ-ChA-1, and RBE cells & $20-160 \mu \mathrm{M}$ & In vitro & $\begin{array}{l}\text { Zhang FH et al. } \\
(2017)\end{array}$ \\
\hline
\end{tabular}

$\mathrm{Ca}^{2+}$ current, and the contraction of colonic smooth muscle through decreasing L-type $\mathrm{Ca}^{2+}$ channel activity (Zhang et al., 2013).

In the Kunming mouse model of diarrhea induced by castor oil, MG (25, 50, and $100 \mathrm{mg} \mathrm{kg}^{-1}$, gavage) significantly inhibited diarrhea, reduced small intestinal transport, and increased catalase (CAT), superoxide dismutase (SOD), and glutathione peroxidase (GSH-Px) (Pang et al., 2013). Zeng et al. found that the antidiarrheal mechanism of MG and honokiol was similar, but in vivo experiments showed that MG had a higher antidiarrheal activity than honokiol (Zeng et al., 2015). The reason might be related to the inhibition of the liver CYP450 enzyme. Deng et al. reported that MG (100, 300 , and $500 \mathrm{mg} \mathrm{kg}^{-1}$, gavage) and honokiol (100,300, and $500 \mathrm{mg} \mathrm{kg}^{-1}$, gavage) regulated the release of IP3-Ca2+ storage, suppressed SK channel, and facilitated the opening of $\mathrm{BKa} 1$ as well as $\mathrm{BK} \beta 3$ channels and the closing of $\mathrm{BK} \beta 4$ channel by blocking the IP3-Ca2+ channel, inhibiting the activation of IP3 receptor 1 and $\mathrm{CaM}$, and regulating protein kinase C (PKC) (Deng et al., 2015). In this study, the dose of MG and honokiol was too high and there was no positive control, so the dose should be reduced, and a positive control should be set for further research.

In conclusion, both MG and honokiol can exhibit gastrointestinal protective activity with similar mechanism, while MG's antidiarrheal activity is better than that of honokiol.

\section{Neuroprotection}

It is worth noting that MG can cross the blood-brain barrier (BBB) (Ranaware et al., 2018). A great quantity of research studies has demonstrated that it has generous pharmacological activities in the nervous system. Cannabinoid (CB) receptors are composed of CB1 and CB2 (Geiger et al., 2010). CB1 receptor activation is involved in the regulation of memory, cognition, and motor control, for example, relieving pain, vomiting, reducing hyperexcitability in epilepsy, stimulating appetite, and euphoria. CB2 receptor activation brings about antinociceptive and inflammatory activities (Fuchs et al., 2013). Studies have found that MG was a partial agonist of $\mathrm{CB} 1\left(\mathrm{EC}_{50}=18.3 \pm 8.6 \mu \mathrm{M}\right)$ and $\mathrm{CB} 2\left(\mathrm{EC}_{50}=3.28 \pm 2.10 \mu \mathrm{M}\right)$, while honokiol was a full agonist of $\mathrm{CB} 1\left(\mathrm{EC}_{50}>10 \mu \mathrm{M}\right)$ and an inverse agonist of CB2. 4'-O-Methylhonokiol was a $\mathrm{CB} 2$ receptor agonist and a potent COX-2 SSI (Chicca et al., 2015). In addition, MG had no activity on GPR-55, while honokiol was an antagonist of GPR-55 (Rempel et al., 2013; Coppola and Mondola, 2014; Fuchs et al., 2014). MG showed a certain preference for $\mathrm{CB} 2$ in binding studies with Ki values for $\mathrm{CB} 1$ and $\mathrm{CB} 2$ of 3.19 and $1.44 \mu \mathrm{M}$, respectively. Ki values of honokiol at $\mathrm{CB} 1$ and $\mathrm{CB} 2$ were 6.46 and $5.61 \mu \mathrm{M}$, respectively (Schuehly et al., 2011; Rempel et al., 2013). The Ki values of $4^{\prime}{ }_{-}$ O-methylhonokiol at CB1 and CB2 were $2.4 \mu \mathrm{M}$ and $188.5 \mathrm{nM}$, respectively (Chicca et al., 2015). MG played an antidepressant role by adjusting the hypothalamic-pituitary-adrenal (HPA) axis and hippocampal neurotransmitters and increasing the 
TABLE 3 | Formulations of MG

Carrier

Proportion

Drug Entrapment efficiency

Solubility

Bioavailability

References

(\%)

(\%)

(mg

$\mathrm{ml}^{-1}$

Pluronic F127 and L61 (8:1; MG-M)

$27.58 \pm$

$81.57 \pm 1.49$

$3.62 \pm 0.02$

The $\mathrm{C}_{\max }, \mathrm{AUC}_{0-\infty}, \mathrm{T}_{\max }$, and $\mathrm{T}_{1 / 2}$ values of

MG-M were $0.823 \mathrm{mg} \mathrm{ml}^{-1}, 4.673 \pm$

$0.31 \mathrm{mg} / \mathrm{ml} \mathrm{h}, 0.75 \pm 0.158 \mathrm{~h}$, and $2.982 \pm$

$0.528 \mathrm{~h}$, respectively. The relative

bioavailability of MG-M was $283 \%$ greate than that of raw MG.

SOL: HS15 40:10

$4.12 \pm 0.16$

$98.37 \pm 1.23$

SOL: TPGS 50: 6

$4.03 \pm 0.19$

Phospholipids, cholesterol, and mPEG2000-DSPE

Soy lecithin

PVP K30

Povidone S-630 (PS-630)

HPC

Eudragit EPO (EPO)

EPC and DPPC

PVP
Phospholipids: cholesterol: mPEG 2000-DSPE: MG 60:8:3:20

Soy lecithin: MG 0.27:0.8

PVPK30:MG 0.27:1.35

PSS-630: MG 6:1

HPC: MG 6:1

EPO: MG 6:

$0.075 \mathrm{mg} \mathrm{mL}^{-1} \mathrm{MG}$

PVP: MG 1:1
$94.61 \pm 0.91$

The $\mathrm{C}_{2} \mathrm{AUC}_{0} \mathrm{~T}_{\max }$, and $\mathrm{T}_{1 / 2}$ values of Ding et

MG-H were $0.837 \pm 0.050 \mu \mathrm{g} \mathrm{ml}^{-1}, 5.127 \pm$ (2018)

$0.988 \mu \mathrm{g} / \mathrm{ml} \mathrm{h}, 0.708 \pm 0.188 \mathrm{~h}$, and

$3.656 \pm 1.212 \mathrm{~h}$, respectively. The relative

oral bioavailability of MG-H increased by

$$
\text { 2.98-fold. }
$$

The $\mathrm{C}_{\max }, \mathrm{AUC}_{0-\infty}, \mathrm{T}_{\max }$, and $\mathrm{T}_{1 / 2}$ values of Ding et al

MG-T were $0.918+0.040 \mathrm{\mu g} \mathrm{ml}^{-1}, 6.027+(2018)$

$0.963 \mathrm{mg} / \mathrm{ml} \mathrm{h}, 0.750 \pm 0.158 \mathrm{~h}$, and

$3.407 \pm 0.855 \mathrm{~h}$, respectively. The relative

oral bioavailability of MG-T increased by

2.39-fold.

Compared with MG solution, the liposome

Shen et al.

had a sustained-release effect.

2016)

- The cumulative dissolution rate was 96.3\%, Liu et al. (2020)

in $12 \mathrm{~h}$. And the bioavailability was increased

by 1.38 times, with the value of $\mathrm{C}_{\mathrm{max}}$ for

$533.62+59.01 \mathrm{ng} \mathrm{ml}^{-1}$

The cumulative dissolution rate was $76.4 \%$, in $12 \mathrm{~h}$. And the bioavailability was increased by 2.12 times, with the value of $\mathrm{C}_{\max }$ for

$721.73 \pm 103.44 \mathrm{ng} \mathrm{ml}^{-1}$.

- $\quad$ The value of relative bioavailability, AUC $\mathrm{T}_{1 / 2}$, and $\mathrm{C}_{\max }$ was $137.22 \%, 823.81 \pm$ $152.63 \mathrm{ng} / \mathrm{L} \mathrm{h}, 6.066 \pm 1.879 \mathrm{~h}$, and $304.59 \pm 136.48 \mathrm{ng} \mathrm{L}^{-1}$.

- $\quad$ The values of bioavailability, $\mathrm{AUC}_{0-\mathrm{t}}, \mathrm{T}_{1 / 2}$, and $\mathrm{C}_{\max }$ were $170.88 \%, 1025.90 \pm$ $149.93 \mathrm{ng} / \mathrm{L} \mathrm{h}, 17.63 \pm 5.020 \mathrm{~h}$, and $151.75 \pm 26.37 \mathrm{ng} \mathrm{L}^{-1}$, respectively. The values of bioavailability, $\mathrm{AUC}_{0-\mathrm{t}}, \mathrm{T}_{1 / 2}$, Lin et al. (2014) and $\mathrm{C}_{\max }$ were $79.50 \%, 477.30 \pm$

$159.46 \mathrm{ng} / \mathrm{L} \mathrm{h}, 13.81 \pm 11.780 \mathrm{~h}$, and

$83.49 \pm 22.37 \mathrm{ng} \mathrm{L}^{-1}$, respectively.

The EPC and DPPC liposomes enhanced Chen (2008) the activity of inhibiting VSMC.

$64.26 \pm 2.92$

The $\mathrm{C}_{\max }, \mathrm{AUC}_{0-\infty}$, and $\mathrm{T}_{\max }$, values of solid Lin et al. (2014) dispersion were $0.6 \pm 0.1 \mathrm{nmol} \mathrm{ml}^{-1}$

$679.0 \pm 130.0 \mathrm{nmol} / \mathrm{ml}^{-1} \mathrm{~min}$, and $275.0 \pm$ $272.6 \mathrm{~min}$, respectively. 
TABLE 3 | (Continued) Formulations of MG.

Drug
Entrapment efficiency
(\%)

Solubility
$\left(\mathrm{mg}^{-1}\right.$

$\mathrm{ml}^{-1}$

$-$

$79.3 \pm 2.2$ $\left(0.2 \mathrm{mg} \mathrm{ml}^{-1}\right)$, $88.4 \pm 2.3$ $\left(0.2 \mathrm{mg} \mathrm{ml}^{-1}\right)$, and $91.6 \pm 0.4$

Oil phase mass fraction of $20 \mathrm{wt} \%$ and an aqueous phase mass fraction of $80 \mathrm{wt} \%$

The amount of MG was $2.0 \mathrm{~g} / 100 \mathrm{ml}$
Distearoyl phosphatidylcholine (DSPC)

DPPC, and dimyristoyl

phosphatidylcholine (DMPC)

HP- $\beta-C D$

Uio-66(Zr)
HP- $\beta$-CD: MG 10:1
$72.16 \pm 2.15$

Compared with free MG, MG-CHC

nanoparticles showed better cell uptake efficiency, antiproliferation, and inhibition of VSMC migration.

$\left(0.2 \mathrm{mg} \mathrm{ml}^{-1}\right)$

$84.87 \pm 1.97$ (DSPC) $75.05 \pm 3.93$ (DPPC), and $67.19 \pm 2.92(\mathrm{DMPC})$
The absolute bioavailability of MG is $17.5 \pm$ 9.7\%. The $\mathrm{AUC}_{0-\infty}, \mathrm{T}_{1 / 2}, \mathrm{CL} / \mathrm{F}$, and $\mathrm{Vd} / \mathrm{F}$ values of $\mathrm{MG}$ emulsion $\left(25 \mathrm{mg} \mathrm{kg}^{-1}\right.$, i.v.) were $6,875 \pm 1,080 \mu \mathrm{g} / \mathrm{ml} \mathrm{h}, 5.49 \pm 1.77 \mathrm{~h}$, $2.9 \pm 0.9 \mathrm{ml} / \mathrm{h} / \mathrm{kg}$, and $0.37 \pm 0.059 \mathrm{ml} / \mathrm{kg}$, respectively. The $C_{\max }, A \cup C_{0-\infty}, T_{\max }, T_{1 / 2}$, $\mathrm{CL} / \mathrm{F}$, and $\mathrm{Vd} / \mathrm{F}$ values of $\mathrm{MG}$ emulsion (50 $\mathrm{mg} \mathrm{kg}^{-1}$, oral administration) were $426.4 \pm 273.8 \mathrm{ng} \mathrm{ml}^{-1}, 2665 \pm 1,306 \mu \mathrm{g} /$ $\mathrm{ml} \mathrm{h}, 1.2 \pm 1.6 \mathrm{~h}, 4.9 \pm 3.0 \mathrm{~h}, 2.2 \pm 1.0 \mathrm{ml}$ $\mathrm{h} / \mathrm{kg}$, and $13.9 \pm 5.1 \mathrm{ml} \mathrm{kg}^{-1}$, respectively.

The three kinds of lipid could increase the inhibition activity of MG to VSMC, and the efficacy of inhibition was DMPC > DPPC > DSPC.

The water solubility of HP- $\beta-C D-M G$ was more than 500 times higher than that of MG and the stability of HP- $\beta$-CD-MG was significantly increased.

The $\mathrm{C}_{\max }, \mathrm{AUC}_{0-\infty}, \mathrm{T}_{\max }$, and $\mathrm{T}_{1 / 2}$ values of MG@Uio-66(Zr) (100 mg kg-1, oral administration) were $3.77 \pm 0.33 \mathrm{\mu g} \mathrm{ml}^{-1}$ $2099.95 \pm 148.48 \mu \mathrm{g} / \mathrm{ml} \mathrm{min}, 196.97 \pm$ $17.38 \mathrm{~min}$, and $206.21 \pm 27.95 \mathrm{~min}$

respectively. The $\mathrm{C}_{\max }, \mathrm{AUC}_{0-\infty}, \mathrm{T}_{\max }$, and $T_{1 / 2}$ values of MG@Uio-66(Zr) (100 mg kg-1, i.p.) were $5.65 \pm 2.41 \mu \mathrm{g} \mathrm{ml}^{-1}, 3831.72 \pm$ $451.57 \mu \mathrm{g} / \mathrm{ml} \mathrm{min}, 114.27 \pm 7.09 \mathrm{~min}$, and $606.35 \pm 114.37 \mathrm{~min}$, respectively. The

relative bioavailability increased almost twofold.

Continued on following page) sheng et a (2014)

Chen (2009) Qiu et al. (2016)

Santos et al. (2020) 

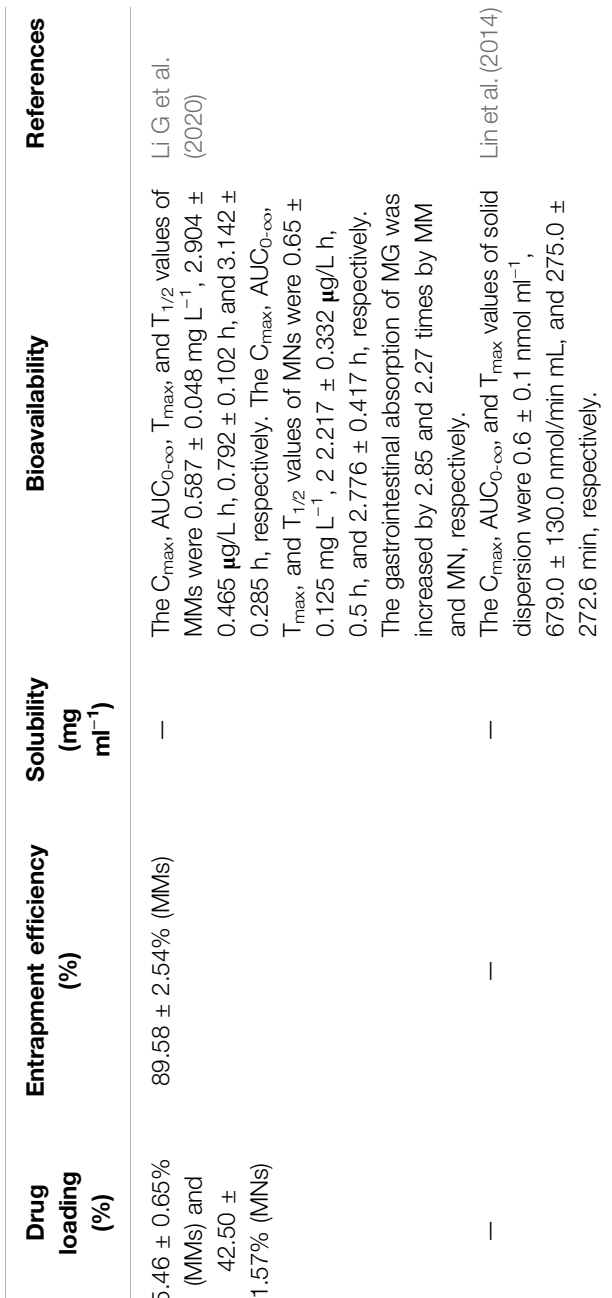
inflammatory cytokines, activating luciferase and liver $\mathrm{X}$ receptor activity, reducing ROS production induced by $\mathrm{A} \beta$, upregulating apolipoprotein $\mathrm{E}$ (ApoE), and promoting microglial phagocytosis and $\mathrm{A} \beta$ degradation (Xie et al., 2020). $\mathrm{MG}\left(\mathrm{EC}_{50}=3.49 \mu \mathrm{M}\right)$ and honokiol $\left(\mathrm{EC}_{50}=2.65 \mu \mathrm{M}\right)$ promoted the transcriptional activities of PPAR- $\gamma$ in a dose-dependent manner. They also dose-dependently increased the luciferase activity of PPAR$\gamma$-LBD. MG and honokiol could fit into the protein pocket of PPAR- $\gamma$-LBD with $\mathrm{IC}_{50}$ values of 3.745 and $16.13 \mu \mathrm{M}$, respectively. What is more, MG had two hydrogen bonds at Glu343, which maintained the binding stability, while honokiol had one hydrogen bond at Glu343 and SER342, respectively, indicating that MG was more effective in enhancing PPAR- $\gamma$ luciferase levels than honokiol (Xie et al., 2020). MG $(5 \mu \mathrm{M})$ significantly inhibited trimethyltin (TMT)-mediated neuronal death and microglial activation by inhibiting ROS production and the activation of JNK, p38 MAPKs, and NF- $\mathrm{kB}$ in HT22 cells and BV-2 cells (Kim and Kim, 2016). Both MG $(12.5 \mu \mathrm{M})$ and honokiol $(6.25 \mu \mathrm{M})$ showed effective behavioral and electrophysiological antiepileptic activities in pentylenetetrazole and ethyl ketopentenoate models (Li G et al., 2020).

At concentrations of 50 and $100 \mathrm{mg} \mathrm{kg}^{-1}$, MG alleviated depression-like behavior in male ICR mice by reducing corticosterone (CORT) level and increasing NE, 5hydroxytryptamine (5-HT), and BDNF protein levels (Bai et al., 2018). It could improve depressive behavior and hippocampal nerve damage in male ddY mice (Matsui et al., 2016). The phosphorylation of Akt, ERK, and cyclic AMPresponsive element-binding protein was significantly increased. In a male Kunming mouse model of chronic mild stress (CMS), 
MG (20 and $40 \mathrm{mg} \mathrm{kg}^{-1}$, gavage) downregulated the levels of interleukin-1 $\beta$ (IL-1 $\beta$ ), IL-6, and tumor necrosis factor- $\alpha$ (TNF$\alpha$ ) in the prefrontal cortex, suppressed the activation of microglia and the proliferation of HPA axis and oxidative stress, and reversed malondialdehyde increase and SOD as well as GSHPX decrease to produce antidepressant-like effect (Cheng et al., 2018). MG (10 and $30 \mathrm{mg} \mathrm{kg}^{-1}$, i.p. injection) downregulated the expression of bax and Ac-FOXO1 and production of NOS, 4HNE, iNOS, phosphorylated p38MAPK, and C/EBP homologs, while upregulated the expressions of Bcl-2 and SIRT1. The regulation effect of $\mathrm{MG}$ on ischemic damage factors may be through inhibiting the production of ROS and upregulating p-Akt and NF-kB (Chen et al., 2014). MG (40 and $80 \mathrm{mg} \mathrm{kg}^{-1}$ ) exhibited antiepileptic activity by prolonging the latency of seizure onset and decreasing the number of seizure spikes, through acting on GABAA/benzodiazepine receptor (Chen CR et al., 2011).

As indicated by the above results, both MG and honokiol can act on $\mathrm{CB} 1$ and $\mathrm{CB} 2$ receptors. The difference is that $\mathrm{MG}$ is a partial agonist of $\mathrm{CB} 1$ and $\mathrm{CB} 2$, while honokiol is a full agonist of $\mathrm{CB} 1$ and an inverse agonist of $\mathrm{CB} 2$, and MG has no activity on GPR-55, while honokiol is an antagonist of GPR-55. MG and honokiol can improve both phasic and tonic GABAergic neurotransmission in hippocampal dentate granule neurons; however, honokiol has a stronger positive regulatory effect on GABAA receptors than MG. In addition, MG and honokiol promote the transcriptional activities of PPAR- $\gamma$ in a dosedependent manner. They also dose-dependently increased the luciferase activity of PPAR- $\gamma$-LBD. However, $M G$ is more effective in enhancing PPAR- $\gamma$ luciferase levels than honokiol. MG had antidepressant, anti-AD, anticonvulsant, antineurological deterioration, and protective effects to brain injury in the nervous system. Honokiol can regulate $\mathrm{CB} 2$ receptor, PPAR- $\gamma$ targets, GABAA, and NF- $\kappa$ B and inhibit the levels of IL-I $\beta$, IL- 6 , IL- 8 , and TNF- $\alpha$, production of ROS, RNS, COX2 as well as iNOS, and expression of PI3K/Akt, MAPKs, ERKs, JNKs, and p38 to exert neuroprotective effects (Talarek et al., 2017).

\section{Interaction with CYP450 Enzyme}

CYP450 is an important enzyme system involved in drug metabolism in vivo (Totah and Rettie, 2005). Among them, CYP2C8, CYP2C9, CYP2E1, and CYP2A6 accounted for about $40 \%$ of the total CYP450 enzymes in the liver (Zhang $\mathrm{P}$ et al., 2017). It is of great significance to study the interaction between the active components of traditional Chinese medicine and CYP450 for clinical safety. Studies have shown that MG can inhibit many CYP enzymes in humans and rats.

The $\mathrm{IC}_{50}$ values of MG on human CYP1A, CYP2C, CYP3A, CYP3A4, CYP2C19, CYP2C8, and CYB2C6 were 5.56, $41.48 \pm$ $5.13,35.0,56.2,0.527,1.62$, and $44.9 \mu \mathrm{M}$, respectively. And the $\mathrm{IC}_{50}$ values of $\mathrm{MG}$ on rat CYP2C, CYP2D6, CYP2E1, CYP3A4, CYP1A2, CYP2B6, CYP1A, CYP3A, CYP2C11, and CYP2D were $5.56 \pm 2.87,65.42 \pm 4.46,67.93 \pm 9.51,52.36 \pm 17.32,97.80 \pm 3.83$, $28.69 \pm 1.46,5.56,3.8,84.5$, and $39.9 \mu \mathrm{M}$, respectively. In addition, $\mathrm{IC}_{50}$ values of $\mathrm{CYP} 2 \mathrm{C} 8, \mathrm{CYP} 2 \mathrm{~A} 1$, and $\mathrm{CYP} 2 \mathrm{~A} 2$ in rat liver and CYP2E1 and CYP2A6 in the human liver were greater than $100 \mu \mathrm{M}$. The inhibition types of MG on CYP1A (Ki: $1.09-12.0 \mu \mathrm{M})$, CYP2C19 (Ki: $0.449 \mu \mathrm{M})$, CYP2C (Ki: 10.0-15.2 $\mu \mathrm{M}$ ), 3A (Ki: 93.7-183 $\mu \mathrm{M})$, and CYP1A2 (Ki: $10.0 \mu \mathrm{M})$ were competitive inhibition. The $\mathrm{IC}_{50}$ values of honokiol on human CYP1A2, CYP2B6, CYP2C8, CYP2C9, CYP2C19, CYP2D6, CYP3A, and CYP3A4 were 3.5, 18.8, $40.8,9.6,32.9,>50,>50$, and $43.9 \mu \mathrm{M}$, respectively. Moreover, the $\mathrm{IC}_{50}$ values of honokiol on rat CYP2C, CYP2A6, CYP2D6, CYP2E1, CYP3A4, CYP1A2, and CYP2B6 were $41.86 \pm 4.24$, $>100,43.43 \pm 2.34,58.10 \pm 3.02,>100,95.24 \pm 7.81$, and $53.22 \pm$ $0.66 \mu \mathrm{M}$, respectively. The inhibition type of honokiol on CYP1A2 (Ki: $6.2 \mu \mathrm{M}$ ) was competitive inhibition, and the inhibition types of honokiol on CYP2E1 (Ki: $11.1 \mu \mathrm{M})$ and CYP2C19 (Ki: $0.702 \mu \mathrm{M})$ were noncompetitive inhibition (Joo and Liu, 2013; Duan et al., 2015; Kim SY et al., 2015; Liu et al., 2016; Zhang P et al., 2017; Huang et al., 2019; Kim S. B. et al., 2015)

Kim et al. proved the feasibility of MG and honokiol to modulate CYP activity in vivo by using the phenacetin and diclofenac as probe substrates for rat CYP1A and 2C, respectively. The result indicated that the mean $\mathrm{IC}_{50}$ values of MG for the metabolism of phenacetin and diclofenac were 19.0 and $47.3 \mu \mathrm{M}$, while those of honokiol were 8.59 and $44.7 \mu \mathrm{M}$, respectively. The inhibitory effect of MG and honokiol on CYP1A activity was stronger than that of CYP2C activity rat liver microsomes (Kim SB et al., 2018). Huang et al. revealed that different CYP450 enzyme isoforms showed different activities in the in vitro metabolism of $\mathrm{MG}$ and honokiol in rat liver microsomes (Huang et al., 2019). The CYP2E1 subtype managed the oxidation of $\mathrm{MG}$ and honokiol terminal double bonds to epoxy metabolites, CYP3A4 seemed to be the main subtype responsible for further hydrolytic metabolism, while CYP1A2 might promote the decarboxylation of metabolites. CYP2A6 might be the key subtype leading to MG hydrogenation. It is necessary to further study the pharmacokinetic interaction between MG and CYP substrate drugs in vitro and in vivo.

\section{Antibacterial Activity}

According to the literature review, MG has antibacterial activities. It could inhibit the Aeromonas hydrophila strains, with the minimal inhibitory concentration (MIC) value range of 32-64 $\mu \mathrm{g} \mathrm{ml}^{-1}$ (Dong et al., 2017). MG and honokiol exhibited similar inhibitory activity against methicillin-resistant Staphylococcus aureus (MRSA) and methicillin-susceptible $S$. aureus (MSSA), with the MIC/minimal bactericidal concentration (MBC) value range of $16-64 \mathrm{mg} \mathrm{L}^{-1}$ (Zuo et al., 2015). Honokiol and MG dose-dependently inhibited the MRSA strain with the MIC values of 33 and $20 \mu \mathrm{g} \mathrm{ml}^{-1}$, respectively (Kim SY et al., 2015). They inhibited multidrug-resistant and MRSA with MIC values in the range of $8-16 \mathrm{ppm}$ (Liu et al., 2014). Choi et al. reported that honokiol and MG caused significant cellular immune-modulatory effect and decreased the production of ROS and inflammatory cytokines/ chemokines during $S$. aureus infection. Honokiol upregulated type I and III interferon mRNA expression in response to MSSA infection and inhibited the growth of MSSA at $2.5 \mu \mathrm{g} \mathrm{ml}^{-1}$ and MRSA at $5 \mu \mathrm{g} \mathrm{ml}^{-1}$, whereas MG inhibited the growth of both 
bacterial cells at $5 \mu \mathrm{g} \mathrm{ml}^{-1}$ after $24 \mathrm{~h}$ of growing (Choi et al., 2015). MG and honokiol could inhibit S. mutans to prevent dental caries, with an MIC value of $10 \mu \mathrm{g} \mathrm{ml}^{-1}$. And MG $\left(50 \mu \mathrm{g} \mathrm{ml}^{-1}\right)$ had better bactericidal activity against $S$. mutans biofilm than honokiol $\left(50 \mu \mathrm{g} \mathrm{ml}^{-1}\right)$ and chlorhexidine $\left(500 \mu \mathrm{g} \mathrm{ml}^{-1}\right)$ at $5 \mathrm{~min}$ after exposure (Sakaue et al., 2016).

In addition, in the seven pathogenic fungi including Alternaria alternata (Fr.) Keissl, Penicillium expansum (Link) Thom, and Alternaria dauci F.Sp. solani, MG inhibited their growth by more than 57\% (Chen Y-H et al., 2019). Moreover, the MIC value ranged from 16 to $64 \mathrm{~g} \mathrm{ml}^{-1}$ for the 64 Candida spp. strains, and the MICs of Candida CSC ${ }^{\star 27907, ~ C D C 27897, ~ C D C 28621, ~ a n d ~}$ ATCC24433 were 64, 32, 16, and $32 \mu \mathrm{g} \mathrm{ml}^{-1}$, respectively. And the average inhibition rate of biofilm was $69.5 \%$ (Behbehani et al., 2017). Honokiol exhibited better antimicrobial activity than MG on Aggregatibacter actinomycetemcomitans, S. mutans, S. aureus, MRSA, and Escherichia coli with MIC/MBC values of 10/10, $10 / 20,10 / 20,10 / 90$, and $>100 />100 \mathrm{~g} \mathrm{ml}^{-1}$, respectively, while those of MG were 10/20,10/20,10/30, 20/90, and >100/> $100 \mathrm{~g} \mathrm{ml}^{-1}$, respectively (Chiu et al., 2020).

Oufensou et al. tested the antifungal activities of MG and honokiol (5-400 $\left.\mathrm{g} \mathrm{ml}^{-1}\right)$ against 32 Fusarium spp. strains. The terbinafine $\left(0.1-10 \mu \mathrm{g} \mathrm{ml}^{-1}\right)$ and fluconazole $\left(1-50 \mu \mathrm{g} \mathrm{ml}^{-1}\right)$ were used as positive controls. The results revealed that MG had similar bactericidal activity compared with fluconazole, whereas honokiol had a better effect of inhibiting the mycelium growth compared to this fungicide. Compared to terbinafine, honokiol exhibited similar antifungal activity, whereas MG was less effective at all selected concentrations (Oufensou et al., 2019).

\section{Antioxidant Activity}

Amorati et al. explored the chemistry behind the antioxidant activity of MG and honokiol. They found that MG trapped four peroxyl radicals, with a $k$ inh of $6.1 \times 104 \mathrm{M}^{-1} \mathrm{~s}^{-1}$ in chlorobenzene and $6.0 \times 103 \mathrm{M}^{-1} \mathrm{~s}^{-1}$ in acetonitrile, while honokiol trapped two peroxyl radicals in chlorobenzene ( $k$ inh $=3.8 \times 104 \mathrm{M}^{-1} \mathrm{~s}^{-1}$ ) and four peroxyl radicals in acetonitrile $\left(k\right.$ inh $\left.=9.5 \times 103 \mathrm{M}^{-1} \mathrm{~s}^{-1}\right)$. Their different behavior was due to the combination of intramolecular hydrogen bonding among the reactive $\mathrm{OH}$ groups (in $\mathrm{MG}$ ) and of the $\mathrm{OH}$ groups with the aromatic and allyl $\pi$-systems (Amorati et al., 2015). MG has a bisphenol core with two allylic side chains, and its antioxidant activity is attributed to hydroxyl and allyl groups (Baschieri et al., 2017). MG downregulated myeloperoxidase (MPO) activity and the expression of TNF- $\alpha$, iNOS, and IL- 6 by altering JNK/ mitochondrial/caspase and PI3K/MEK/ERK/Akt/FoxO1 signaling pathways (Shih et al., 2012; Dong et al., 2013).

In vitro, $\mathrm{MG}(16 \mu \mathrm{M})$ protected against acrolein-induced oxidative stress in human SH-SY5Ycells via acting on JNK/ mitochondrial/caspase and PI3K/MEK/ERK/Akt/FoxO1 signaling pathways and inhibiting intracellular glutathione consumption as well as ROS accumulation (Dong et al., 2013).

It was found that $\mathrm{MG}\left(20 \mathrm{mg} \mathrm{g}^{-1}\right.$, i.v. injection) could significantly reduce MPO activity and the expression of iNOS, TNF- $\alpha$, and IL- 6 to inhibit oxidative stress and reduce mesenteric reperfusion caused lung injury in male $\mathrm{C} 3 \mathrm{H} / \mathrm{HeOuJ}$ mice (Shih et al., 2012). In aristolochic acid (AA)-induced HK-2 cells, MG $(10 \mu \mathrm{M})$ and honokiol $(10 \mu \mathrm{M})$ effectively reduced oxidative stress and suppressed cell proliferation by blocking the cell cycle at the G1 phase and preventing the G2/M arrest (Bunel et al., 2016).

\section{Other Activities}

Besides these pharmacological activities mentioned above, MG also has the following activities: inhibition of osteoclast differentiation, antiphotoaging, antiparasitic, antiviral activity, and reduction of multidrug resistance.

MG $(0.1 \mu \mathrm{M})$ significantly downregulated the production of osteoclast differentiation-inducing factors such as RANKL, TNF$\alpha$, and IL- 6 and inhibited mitochondrial electron transport (Kwak et al., 2012). In RANKL-induced RAW 264.7 macrophages, MG $(75-150 \mu \mathrm{M})$ decreased osteoclast differentiation, tartrateresistant acid phosphatase activity of differentiated cells, and resorption pit area caused by osteoclasts in a concentrationmanner (Lu et al., 2013). MG $(10 \mu \mathrm{M})$ inhibited IL-1-induced RANKL expression and osteoclast differentiation by suppressing COX-2 expression and PGE2 production (Hwang et al., 2018). MG $(2.5-20 \mu \mathrm{M})$ attenuated RANKL-induced osteoclast differentiation by suppressing MAPK/c-fos/AP-1 and NF- $\kappa B$ signaling, inhibiting ROS production, and increasing $\mathrm{HO}-1$ expression ( $\mathrm{Lu}$ et al., 2015a). In tendon-derived stem cells (TDSCs), MG $(5-20 \mu \mathrm{M})$ prevented calcium deposition and osteogenic differentiation of tendon-derived stem cells through influencing $\mathrm{PI} 3 \mathrm{~K} / \mathrm{Akt} / \beta$-catenin pathway induced by PEG-2 (Zhou $W$ et al., 2019). In ligature-induced rats, MG (100 $\mathrm{mg} \mathrm{kg}^{-1}$, p.o.) significantly suppressed alveolar bone resorption, the number of osteoclasts on the bony surface, and the expression of RANKL. Moreover, it could reduce the expression of MMP-1, MMP-9, iNOS, and COX-2 and TNF- $\alpha$ activation ( $\mathrm{Lu}$ et al., 2013). MG (25 $\mathrm{mg} \mathrm{kg}^{-1}$, i.p. injection) inhibited the activities of osteogenic factors runt-related transcription factor 2(RUNX2), OCN, and bone morphogenetic protein 2 (BMP2) in male SD rats. Moreover, it inhibited ossification of tendon ossification by reducing heterotopic ossification of Achilles tendon (Zhou W et al., 2019).

After treating HR-1 hairless male mice with $40 \mu \mathrm{L}$ of the $0.25 \%$ MG preparation, it significantly reduced the average length and depth of wrinkles and inhibited the expression of MMP-1, MMP9, and MMP-13 to play a role in antiphotoaging activity (Im et al., 2015).

MG significantly inhibited $\mathrm{HBV}$ activities. The $\mathrm{IC}_{50}$ values of $\mathrm{HBV}$ surface antigen (HBsAg), HBV e antigen ( $\mathrm{HBeAg}$ ), and replication of $\mathrm{HBV}$ DNA were 2.03, 3.76, and $8.67 \mu \mathrm{M}$, respectively, and without cytotoxicity to $\mathrm{HBsAg}$ and $\mathrm{HBeAg}$ (Li J et al., 2013). MG $\left(2.51 \pm 0.51 \mu \mathrm{g} \mathrm{ml}^{-1}\right)$ and honokiol $\left(3.18 \pm 0.61 \mu \mathrm{g} \mathrm{ml}^{-1}\right)$ stimulated the expression of immunerelated genes to resist grass carp reovirus infection in Ctenopharyngodon idella kidney (CIK) cells. MG significantly increased the expression of interferon (IFN) regulatory factor (IRF) 7 and IL- $1 \beta$ to activate type I IFN (IFN-I) but failed to induce the molecules in NF- $\kappa B$ pathways. The difference was that honokiol promoted the expression of IL- $1 \beta, \mathrm{TNF} \alpha, \mathrm{NF}-\kappa \mathrm{B}, \mathrm{IFN}-\beta$, promoter stimulator $1, \mathrm{IRF} 3$, and 
IRF7 but failed to increase IFN-I expression, showing that it could enhance the host innate antiviral response to grass carp reovirus infection by regulating NF- $\kappa \mathrm{B}$ pathway (Chen et al., 2017).

What is more, MG $(1-50 \mu \mathrm{M})$ reduced the multidrug resistance of cancer cells to antitumor drugs through downregulating P-glycoprotein expression in a concentrationand time-dependent manner and increased the intracellular accumulation of calcein in NCI/ADR-RES cells (Han and Van Anh, 2012).

\section{TOXICITY}

So far, a large number of studies have shown that MG has cytotoxicity (Table 2). MG (10-100 $\mu \mathrm{M}, 24$ or $48 \mathrm{~h})$ was used to investigate the toxicity on human normal hepatocyte U937 and LO-2 cells. The results showed that MG at low concentration could promote the cell survival rate in a dose-dependent manner. At a concentration of less than $60 \mu \mathrm{M}, \mathrm{MG}$ could promote the survival of U937 cells. When exposed to MG at a concentration of less than $70 \mu \mathrm{M}$ after $48 \mathrm{~h}$, the mortality of LO-2 cells was lower than 20\% (Chen $\mathrm{H}$ et al., 2019). Additionally, at a concentration range from 50 to $200 \mu \mathrm{g} \mathrm{ml}^{-1}$, MG could cause toxicity and inhibit MMEC survival (Wei et al., 2014).

Karki et al. reported that MG at a concentration of $40 \mu \mathrm{M}$ possessed cytotoxicity on VSMCs (Karki et al., 2013a). MG $(100 \mu \mathrm{M})$ reduced the murine 3T3-F442A preadipocyte viability by $25 \%$ and human normal subcutaneous preadipocyte viability by $36 \%$. MG $(50 \mu \mathrm{M})$ reduced the murine cell viability by $16 \%$ and human cell viability by $22 \%$. Otherwise, honokiol $(50 \mu \mathrm{M})$ significantly decreased the murine and human cell viability by 30 and $39 \%$, and the combined application of honokiol and MG $(100 \mu \mathrm{M}$ each) markedly decreased the cell viability by $73 \%$ (murine) and $80 \%$ (human). The combined application of honokiol and $\mathrm{MG}$ $(50 \mu \mathrm{M}$ each) also markedly reduced murine (31\%) and human $(37 \%)$ cell viability. On the contrary, the simultaneous application of honokiol and MG $(30 \mu \mathrm{M}$ each) only moderately affected the murine (15\%) and human (21\%) cell viability (Alonso-Castro et al., 2011). When the concentration of MG was $>50 \mu \mathrm{M}$, it would be toxic to mES-derived endothelial-like cells (Kim GD et al., 2013). Liu et al. studied the cytotoxicity of MG on human breast cancer cell lines and normal human mammary epithelial cells. The results showed that $\mathrm{MG}$ had moderate cytotoxicity to MCF-10A, MCF-7, SK-BR3, MDAMB-453, MDA-MB-435S, MDA-MB-231, and MDA-MB-468 cells with $\mathrm{IC}_{50}$ values of $70.52 \pm 5.09,36.46 \pm 2.38,59.40 \pm$ $8.24,35.69 \pm 4.91,25.39 \pm 3.26,25.32 \pm 2.72$, and $24.79 \pm$ $3.06 \mu \mathrm{M}$, respectively (Liu et al., 2013). Park et al. treated HCT-116 colon cancer cells with various concentrations of MG $(0-50 \mu \mathrm{M})$ for 24 and $48 \mathrm{~h}$. MG induced cell death in a dose- and time-dependent manner. Treatment with $50 \mu \mathrm{M} \mathrm{MG}$ for $24 \mathrm{~h}$ resulted in significant decreases in cell viability with $75.3 \%$ of the cells surviving after $24 \mathrm{~h}$ and $81.7 \%$ of the cells surviving after $48 \mathrm{~h}$. Moreover, MG $(50 \mu \mathrm{M})$ induced apoptosis in $76.1 \%$ of the cells after $24 \mathrm{~h}$, indicating that MG inhibited cell proliferation and induced apoptosis in HCT-116 cells (Park et al., 2012). When OC2 cells were treated with MG $(20-100 \mu \mathrm{M})$ for $24 \mathrm{~h}$, the cell viability decreased in a dose-dependent manner (Hsieh et al., 2018). After treating A549 cells with 6.25, 12.5, 25, 50,100 , and $200 \mu \mathrm{M}$ of MG for 24 and $48 \mathrm{~h}$, cell viability for $24 \mathrm{~h}$ was $98.1 \pm 2.7,86.4 \pm 2.3,79.5 \pm 4.6,68.7 \pm 2.3,55.9 \pm 1.1$, and $12.8 \pm 3.1 \%$, respectively, while for $48 \mathrm{~h}$ was $92.5 \pm 3.5,80.1 \pm 4.7$, $70.2 \pm 2.8,56.6 \pm 3.4,36.3 \pm 2.6$, and $3.1 \pm 0.9 \%$, respectively. When the dose of MG was $\leq 6.25 \mu \mathrm{M}$, there was almost no inhibitory effect on A549 cells, while $25 \mu \mathrm{M}$ of $\mathrm{MG}$ significantly inhibited the proliferation of A549 cells. MG inhibited the proliferation of A549 cells in a dose- and timedependent manner (Wu et al., 2014). In DU145 cells, the viability was reduced by 30 and $60 \%$ at 40 and $80 \mu \mathrm{M}$, respectively, after $6 \mathrm{~h}$ of MG treatment, and 49 and $76 \%$ were reduced at 40 and $80 \mu \mathrm{M}$, respectively, after $24 \mathrm{~h}$ of $\mathrm{MG}$ treatment. After treating PC3 cells with $80 \mu \mathrm{M}$ MG for 6 and $24 \mathrm{~h}$, its viability decreased to 50 and $48 \%$, respectively (McKeown et al., 2014). Li et al. treated GBC cells with MG at concentrations of 10,20 , and $30 \mu \mathrm{M}$ for $48 \mathrm{~h}$. The results showed that the apoptosis index of GBC cells was significantly higher than that of the control group ( $\mathrm{Li}$ et al., 2015). SGC-7901 cells were treated with different concentrations of MG $(0,10,30,50,100,200$, and $300 \mu \mathrm{M})$ for $48 \mathrm{~h}$. It was observed that MG inhibited cell growth in a dose-dependent manner. Compared with the control group, exposing cells to 40,60, and $80 \mu \mathrm{M}$ of $\mathrm{MG}$ for $48 \mathrm{~h}$ resulted in a significant reduction in the number of cells (Rasul et al., 2012). MG significantly suppressed the proliferation of SKOV 3 and TOV21G cells in a dose-dependent $(6.25,12.5,25,50$, and $100 \mu \mathrm{M})$ and time-dependent (48 and $72 \mathrm{~h})$ manner (Chuang et al., 2011). The QBC939, SK-ChA-1, MZ-ChA1 , and RBE cells were treated with different concentrations of MG $(20,40,80$, and $160 \mu \mathrm{M})$ for 24,48 , and $72 \mathrm{~h}$. The results demonstrated that MG significantly suppressed the proliferation of the above cell lines in a concentration- and time-dependent manner (Zhang FH et al., 2017).

Fujita et al. investigated the ability of MG and honokiol to inhibit UV-induced mutation in Salmonella typhimurium TAI02. The results suggested that both MG $(5 \mu \mathrm{g} /$ per plate $)$ and honokiol $(5 \mu \mathrm{g} /$ per plate) could inhibit against UV-induced mutations by scavenging $\cdot \mathrm{OH}$ generated by $\mathrm{UV}$ irradiation. The relative mutagenic activities of MG and honokiol were $62 \pm 1 \%$ and $62 \pm 4 \%$, respectively, while that of control was $100 \%$ (Fujita and Taira, 1994). MG significantly inhibited the mutagenicity induced by indirect mutagens but did not affect the direct mutagens. It strongly and competitively inhibited the activities of ethoxyresorcinol-O-demethylase and methoxyresorcinol-Odemethylase, indicating that it could inhibit indirect mutageninduced mutations by suppressing the activities of CYP1A1 and CYP1A2 (Saito et al., 2006). The genotoxicity of Magnolia bark extract (MBE) was studied by Li et al., which was composed of 94\% MG and 1.5\% honokiol. The results revealed that MBE was not genotoxic under the conditions of the in vitro bacterial reverse mutation test and in vivo micronucleus test and supported the safety of MBE for dietary consumption (Li et al., 2007).

In general, the abovementioned cytotoxicity is mostly related to the antitumor and antiangiogenic activities of MG. Additionally, studies have shown that MG not only has no 
mutagenic and genotoxic activity but also even has antimutagenic activity. In summary, MG was found to be fairly nontoxic.

\section{BIOAVAILABILITY AND FORMULATION}

MG is a dimeric phenolic neolignan (Pulvirenti et al., 2017) with strong lipid solubility, and its absorption in the gastrointestinal tract is mainly through a lipid-like pathway (Niu et al., 2015). Hatorri et al. studied the absorption, metabolism, and excretion of MG through oral administration and intraperitoneal injection of [ring- $\left.{ }^{14} \mathrm{C}\right] \mathrm{MG}$. The results showed that MG participated in enterohepatic circulation (Hattori et al., 1986). After oral administration of $\mathrm{MG}\left(50 \mathrm{mg} \mathrm{kg}^{-1}\right)$, the $\mathrm{MG}$ sulfates and glucuronides were predominant in the bloodstream. And MG was mainly distributed in the liver, kidney, brain, lung, and heart; among these organs, the concentration of $\mathrm{MG}$ and $\mathrm{MG}$ glucuronides in the liver was the highest (Lin et al., 2011). Additionally, MG's main metabolite excreted in bile was magnolol-2-O-glucuronide, and the main route of excretion of MG after oral or intraperitoneal injection was through the alimentary tract (Hattori et al., 1986). After $24 \mathrm{~h}$ of oral administration of [ring- ${ }^{14} \mathrm{C}$ ] MG, the main fecal derivatives of oral MG in rats were MG and a series of free form metabolites, which accounted for more than $90 \%$ of the total dose; only $6 \%$ were glucuronic acid and sulfate (Hattori et al., 1986). The MG metabolites tetrahydromagnolol and trans-isomagnolol showed an increasing trend after repeated administration, indicating that their formation was related to the induction of metabolic enzymes in animal tissues and/or intestinal bacteria. It was mainly excreted through liver metabolism and renal excretion (Hattori et al., 1986). The absorption half-life, elimination half-life $\left(T_{1 / 2}\right)$, maximum concentration-time $\left(\mathrm{T}_{\max }\right)$, and maximum concentration $\left(\mathrm{C}_{\max }\right)$ of $\mathrm{MG}$ were $0.63 \mathrm{~h}, 2.33 \mathrm{~h}, 1.12 \mathrm{~h}$, and $0.16 \mu \mathrm{g} \mathrm{ml}^{-1}$, respectively. The water solubility and gastrointestinal absorption of MG were poor, with the oral bioavailability of only $4.9 \%$ (Tsai et al., 1996), limiting its clinical use. The low bioavailability might be partly due to the high metabolism of the intestine and liver and the low solubility in gastric juice.

In recent years, the bioavailability of MG has been significantly improved by various formulations including solid dispersion (Ochiuz et al., 2016; Tang et al., 2016; Stefanache et al., 2017b; Stefanache et al., 2017a; Li et al., 2019), phospholipid complex (Liu et al., 2020), liposome (Chen, 2008; Chen, 2009; Shen et al., 2016), nanoparticles (Wang et al., 2011), emulsion (Sheng et al., 2014), mixed micelles (Shen $\mathrm{H}$ et al., 2018; Ding et al., 2018), $\beta$-cyclodextrin inclusion compound (Qiu et al., 2016), and Zrbased organometallic framework (Santos et al., 2020) (Table 3).

Liu et al. prepared MG solid dispersion, MG solid lipid nanoparticles, and MG phospholipid complex and studied their bioavailability. The results showed that the cumulative dissolution of MG was $30.6 \%$ within $12 \mathrm{~h}$, while the cumulative dissolution of MG solid dispersion, MG solid lipid nanoparticles, and MG phospholipid complex increased to 96.3, 76.4 , and $45.9 \%$, respectively. The pharmacokinetic parameters such as $\mathrm{C}_{\max }$ and area under the curve $(\mathrm{AUC})_{0-\mathrm{t}}$ and $\mathrm{AUC}_{0-\infty}$ were significantly improved. Moreover, compared with raw MG, their relative bioavailability increased to $1.38,2.12$, and 3.45 times, respectively (Liu et al., 2020). All three preparations could improve the oral absorption bioavailability of MG, but the effect of MG solid lipid nanoparticles was more obvious. Lin et al. prepared a solid dispersion of MG with polyvinylpyrrolidone K-30 (PVP) and studied its bioavailability by oral administration $\left(50 \mathrm{mg} \mathrm{kg}^{-1}\right)$. The results indicated that compared with raw MG, the solid dispersion of MG with PVP significantly increased the systemic exposures of MG and MG sulfates/glucuronides by 80.1 and $142.8 \%$, respectively (Lin et al., 2014). For the solid dispersion prepared by $\mathrm{MG}$ and croscarmellose sodium (1: 5), the in vitro cumulative dissolution rate of $\mathrm{MG}$ reached $80.66 \%$ at 120 min, which was 6.9 times that of the raw MG (11.74\%) (Tang et al., 2016). Stefanache et al. incorporated MG into the pores of amino-functionalized mesoporous silica particles to increase the dosage of MG and delay its release (Stefanache et al., 2017a).

After gavaging the emulsion $\left(50 \mathrm{mg} \mathrm{kg}^{-1}\right)$ in male SD rats, the $1.20 \mathrm{~h}$ average plasma concentration of MG was $426.4727 \mathrm{ng} \mathrm{ml}^{-1}$, and the absolute bioavailability was $17.579 \%$, indicating that preparing an emulsion could improve the bioavailability of MG (Sheng et al., 2014).

Chen used 1,2-diacyl-Sn-glycero-3-phosphocholine (EPC) and 1,2-dipalmitoyl- Sn-glycero-3-phosphocholine (DPPC) liposomes to encapsulate $\mathrm{MG}$ with entrapment efficiencies of $74.13 \pm 1.97 \%$ and $64.26 \pm 2.92 \%$, respectively. The results showed that EPC and DPPC liposomes enhanced the inhibitory effect of MG on VSMCs, and the inhibitory effect of EPC liposome-encapsulated MG on VSMCs was better than that of DPPC liposome (Chen, 2008). Qiu et al. utilized hydroxypropyl- $\beta$-cyclodextrin (HP- $\beta-\mathrm{CD}$ ) to prepare MG-HP$\beta-\mathrm{CD}$ inclusion complex (HP- $\beta-\mathrm{CD}$ : MG 10:1). The stoichiometric ratio of the inclusion compound was 1:1, and the stability constant $(\mathrm{Kc})$ was calculated as $2206 \mathrm{M}^{-1}$. In addition, the aqueous solubility of the MG-HP- $\beta-\mathrm{CD}$ inclusion complex was more than 500 -fold that of free MG, and it had better stability and stronger antitumor activity in vitro (Qiu et al., 2016). Santos et al. used Uio-66 $(\mathrm{Zr})$ as the MG carrier. After oral or intraperitoneal administration of $100 \mathrm{mg} \mathrm{kg}^{-1}$ of MG and MG@Uio-66(Zr), the AUC $_{0-720}$ of MG@Uio-66(Zr) (op:1823 $\pm 167.31 \mu \mathrm{g} / \mathrm{ml}$ min, i.p.: $2312.67 \pm 253.76 \mu \mathrm{g} / \mathrm{ml} \mathrm{min}$ ) was significantly higher than the $\mathrm{AUC}_{0-720}$ of free MG (op: $823.3 \pm 139.10 \mu \mathrm{g} / \mathrm{ml} \mathrm{min}$, i.p.: $2582.67 \pm 150.48 \mu \mathrm{g} / \mathrm{ml} \mathrm{min}$ ). The relative bioavailability of $\mathrm{MG}$ increased almost twofold by using Uio-66(Zr) (Santos et al., 2020). The drug loading efficiency of MG-carboxymethyl-hexanoyl chitosan $(\mathrm{CHC})$ nanoparticles was in the range of $91.6 \pm 0.4$ to $79.3 \pm 2.2 \%$, depending on the initial MG concentration of $0.05-0.2 \mathrm{mg} \mathrm{mL}^{-1}$. MG-CHC nanoparticles had excellent cell uptake efficiency. Compared with free MG, it could be effectively delivered within the cell, which increased the resistance proliferation and inhibition of VSMC migration (Wang et al., 2011).

Mixed Soluplus (SOL) and Solutol HS15 (HS15), SOL, and D-alpha-tocopheryl polyethylene glycol 1,000 succinate (TPGS) were used to prepare MG-loaded mixed micelles (MG-M) MG-H and MG-T, respectively. The relative oral bioavailability of MG-T and MG-H were increased by 2.39 - and 2.98 -fold, respectively, compared to that of raw MG, indicating that MG-H and MG-T 
could promote the absorption of MG in the gastrointestinal tract (Ding et al., 2018). Shen et al. also prepared MG-M by pluronic F127 and L61, and its drug loading efficiency and entrapment efficiency were $81.57 \pm 1.49 \%$ and $27.58 \pm 0.53 \%$, respectively. In vitro release test showed that MG had sustained release behavior after being encapsulated in micelles. The permeability of MG through the Caco- 2 cell monolayer was enhanced, and the relative bioavailability of oral MG-M was 2.83 times higher than that of the raw MG (Shen $\mathrm{H}$ et al., 2018). It can be seen that the mixed micelle drug delivery system can improve the poor water solubility and bioavailability of MG.

In general, the existing formulations can not only improve the water solubility and bioavailability of MG but also improve its stability, enhance its pharmacological effects, and enable MG to have a sustained release behavior, which will provide strategies for future clinical applications of MG.

\section{CONCLUSION}

In 2011, Chen et al. summarized the pharmacological activities and molecular mechanisms of MG. According to the review, MG could exhibit anti-inflammatory activity by inhibiting the production of inflammatory enzymes/cytokines and activation of NF- $\kappa \mathrm{B}$ and leukocyte. It also exerted antitumor effects by inhibiting cell proliferation and metastasis and inducing apoptosis. The molecular mechanisms mainly include the increase of p21, p27, caspase-3, caspase-8, and caspase-9 expression, inhibition of PI3K/ PTEN/AKT pathway, ERK1/2, NF-kB, P38, iNOS, and COX2 activation, CYP1A1, CYP1A2, MMP-9 as well as MMP-2 activity and $\mathrm{Bcl}-2$ expression, induction of cytochrome $\mathrm{C}$, and AIF release and activation of the mitochondrial death receptor pathway. MG could attenuate VCAM-1, ICAM-1, MCP-1, and MMP9, inhibit the proliferation of smooth muscle cells and fibroblasts, and obtain arrhythmia from I/R injury to show cardiovascular protection. It could also exert neuroprotective activities by inhibiting the production of PGE2, regulating $(\mathrm{GABA})_{\mathrm{A}}$ receptor subtypes and central serotonergic activity, retaining cholinergic neurons in the forebrain, and inhibiting cortical 5-HT release. MG had a therapeutic effect on gastrointestinal diseases by regulating serotonergic and gastrointestinal system functions and relaxing gastrointestinal smooth muscles. Moreover, it exhibited hypoglycemic activity by activating PPAR and increasing basal and insulin-stimulated glucose uptake (Chen YH et al., 2011).

In this review, in vivo and in vitro studies demonstrated that MG has a wide range of pharmacological activities including anti-inflammatory, antitumor, antioxidant, hypoglycemic, cardiovascular protection, antiangiogenesis, and antibacterial. MG inhibited TLR2/TLR4/NF$\kappa \mathrm{B} / \mathrm{MAPK} / \mathrm{PPAR}-\gamma$ pathways and decreased the expression of inflammatory cytokines to exhibit anti-inflammatory activity. It suppressed the growth, migration, and invasion of tumor cells and promoted apoptosis as well as autophagy, through acting on caspase-8, caspase- 3 , and other proteins participated in the p53, MAPK, NF- $\mathrm{kB}$, TLR, PI3K/Akt/mTOR, and Wnt/ $\beta$-catenin signaling pathways. It also protected the nervous system through multiple systems and multiple targets. Moreover, it has a wide range of antibacterial activity. MG is a candidate drug for anti-inflammatory, anticancer, and neuroprotective activities. However, MG's in vivo effect with CYP enzymes is not clear yet, and there is no clinical research on MG, which cannot fully provide the pharmacological activities of it.

MG and honokiol have similar pharmacological activities. Both of them can exhibit antitumor activities by regulating MAPK, NF$\kappa \mathrm{B}, \mathrm{HIF}-\alpha, \mathrm{PI} 3 \mathrm{~K} / \mathrm{Akt} / \mathrm{ERK} / \mathrm{mTOR}$, and $\mathrm{Wnt} / \beta$-catenin signaling pathways. MG shows antitumor activity by regulating TLR signaling pathways, and honokiol can regulate STAF, EGFR, and notch signaling pathways to exhibit antitumor activities. They have inhibitory activity on a-glucosidase and stimulation of glucose uptake to play a hypoglycemic role, while MG has a better inhibitory effect of a-glucosidase. Moreover, both MG and honokiol exhibit gastrointestinal protective activity with similar mechanism, while MG's antidiarrheal activity is better than that of honokiol. MG is a partial agonist of CB1 and CB2; however, honokiol is a full agonist of $\mathrm{CB} 1$ and an inverse agonist of CB2. MG has no activity on GPR-55, while honokiol is an antagonist of GPR55. Honokiol has a stronger positive regulatory effect on GABAA receptors than MG; however, MG is more effective in enhancing PPAR- $\gamma$ luciferase levels than honokiol. What is more, the inhibition types of MG on CYP1A, CYP2C19, CYP2C, CYP3A, and CYP1A2 were competitive inhibition. The inhibition type of honokiol on CYP1A2 was competitive inhibition, and the inhibition types of honokiol on CYP2E1 and CYP2C19 were noncompetitive inhibition. Both honokiol and MG have antimicrobial activity. The difference is that honokiol exhibits better antimicrobial activity than MG on Aggregatibacter actinomycetemcomitans, S. mutans, S. aureus, MRSA, Escherichia coli, and Fusarium spp.

MG is nontoxic and is used in dietary supplements and cosmetic products, such as added to toothpaste to play antibacterial and antiperiodontitis effects. However, the low water solubility, poor bioavailability, and skin irritation hamper its application. To overcome this problem, numerous studies have been conducted. By preparing solid dispersions, nanoparticles, phospholipid complexes, liposomes, emulsions, etc., the bioavailability and stability of MG significantly improved, which will greatly promote its clinical application. Aside from its formulations, structural modification is becoming an increasingly promising method for obtaining MG derivatives with better therapeutic effects and higher bioavailability. The synthesis and research of MG derivatives are beyond the scope of this study, so we will not go into details. Consequently, the design and research of MG derivatives are of great significance in the future.

In summary, this article comprehensively reviews the pharmacology, toxicity, bioavailability, and formulations of MG.

\section{AUTHOR CONTRIBUTIONS}

YL and YS contributed to the conception and design of the study; YL, YL, and YZ prepared the original draft; BT, XQ, and QY reviewed and edited the manuscript; YS supervised the study. 


\section{REFERENCES}

Alexeev, M., Grosenbaugh, D. K., Mott, D. D., and Fisher, J. L. (2012). The natural products magnolol and honokiol are positive allosteric modulators of both synaptic and extra-synaptic GABA A receptors. Neuropharmacology 62, 2507-2514. doi:10.1016/j.neuropharm.2012.03.002

Alonso-Castro, A. J., Zapata-Bustos, R., Domínguez, F., García-Carrancá, A., and Salazar-Olivo, L. A. (2011). Magnolia dealbata Zucc and its active principles honokiol and magnolol stimulate glucose uptake in murine and human adipocytes using the insulin-signaling pathway. Phytomedicine 18, 926-933. doi:10.1016/j.phymed.2011.02.015

Amorati, R., Zotova, J., Baschieri, A., and Valgimigli, L. (2015). Antioxidant activity of magnolol and honokiol: kinetic and mechanistic investigations of their reaction with peroxyl radicals. J. Org. Chem. 80, 10651-10659. doi:10.1021/acs. joc.5b01772

Bai, Y., Song, L., Dai, G., Xu, M., Zhu, L., Zhang, W., et al. (2018). Antidepressant effects of magnolol in a mouse model of depression induced by chronic corticosterone injection. Steroids 135, 73-78. doi:10.1016/j.steroids.2018.03.005

Banik, K., Ranaware, A. M., Deshpande, V., Nalawade, S. P., Padmavathi, G., Bordoloi, D., et al. (2019). Honokiol for cancer therapeutics: a traditional medicine that can modulate multiple oncogenic targets. Pharmacol. Res. 144, 192-209. doi:10.1016/j.phrs.2019.04.004

Baschieri, A., Pulvirenti, L., Muccilli, V., Amorati, R., and Tringali, C. (2017). Chain-breaking antioxidant activity of hydroxylated and methoxylated magnolol derivatives: the role of H-bonds. Org. Biomol. Chem. 15, 6177-6184. doi:10.1039/c7ob01195d

Behbehani, J., Shreaz, S., Irshad, M., and Karched, M. (2017). The natural compound magnolol affects growth, biofilm formation, and ultrastructure of oral Candida isolates. Microb. Pathog. 113, 209-217. doi:10.1016/j.micpath. 2017.10.040

Biersack, B. (2018). Relations between approved platinum drugs and non-coding RNAs in mesothelioma. Non-coding RNA Res. 3, 161-173. doi:10.1016/j.ncrna. 2018.08.001

Bunel, V., Antoine, M. H., Stévigny, C., Nortier, J., and Duez, P. (2016). New in vitro insights on a cell death pathway induced by magnolol and honokiol in aristolochic acid tubulotoxicity. Food Chem. Toxicol. 87, 77-87. doi:10.1016/j. fct.2015.11.020

Chang, H., Chang, C. Y., Lee, H. J., Chou, C. Y., and Chou, T. C. (2018). Magnolol ameliorates pneumonectomy and monocrotaline-induced pulmonary arterial hypertension in rats through inhibition of angiotensin II and endothelin-1 expression. Phytomedicine 51, 205-213. doi:10.1016/j.phymed.2018.10.001

Chao, L., CaO, Y., Chen, P., and Zhang, L. (2018). Study on the effect of Magnoliae Officinalis Cortex on gastrointestinal motility disorders. China Med. Her. 15, 31-34.

Chen, C. Y. C. (2008). Inhibiting the vascular smooth muscle cells proliferation by EPC and DPPC liposomes encapsulated Magnolol. J. Chin. Inst. Chem. Eng. 39, 407-411. doi:10.1016/j.jcice.2008.04.005

Chen, C. Y. C. (2009). Magnolol encapsulated by different acyl chain length of liposomes on inhibiting proliferation of smooth muscle cells. J. Taiwan Inst. Chem. Eng. 40, 380-386. doi:10.1016/j.jtice.2008.10.006

Chen, C. R., Tan, R., Qu, W. M., Wu, Z., Wang, Y., Urade, Y., et al. (2011). Magnolol, a major bioactive constituent of the bark of Magnolia officinalis, exerts antiepileptic effects via the GABA/benzodiazepine receptor complex in mice. Br. J. Pharmacol. 164, 1534-1546. doi:10.1111/j.1476-5381.2011.01456.x

Chen, H., Fu, W., Chen, H., You, S., Liu, X., Yang, Y., et al. (2019). Magnolol attenuates the inflammation and enhances phagocytosis through the activation of MAPK, NF- $\mathrm{kB}$ signal pathways in vitro and in vivo. Mol. Immunol. 105, 96-106. doi:10.1016/j.molimm.2018.11.008

Chen, J. H., Kuo, H. C., Lee, K. F., and Tsai, T. H. (2014). Magnolol protects neurons against ischemia injury via the downregulation of p38/MAPK, CHOP and nitrotyrosine. Toxicol. Appl. Pharmacol. 279, 294-302. doi:10.1016/j.taap. 2014.07.005

Chen, M. C., Lee, C. F., Huang, W. H., and Chou, T. C. (2013). Magnolol suppresses hypoxia-induced angiogenesis via inhibition of HIF-1a/VEGF signaling pathway in human bladder cancer cells. Biochem. Pharmacol. 85, 1278-1287. doi:10.1016/j.bcp.2013.02.009

Chen, X., Hu, Y., Shan, L., Yu, X., Hao, K., and Wang, G. xue. (2017). Magnolol and honokiol from Magnolia officinalis enhanced antiviral immune responses against grass carp reovirus in Ctenopharyngodon idella kidney cells. Fish Shellfish Immunol. 63, 245-254. doi:10.1016/j.fsi.2017.02.020

Chen, Y.-H., Lu, M.-H., Guo, D.-S., Zhai, Y.-Y., Miao, D., Yue, J., et al. (2019). Antifungal Effect of magnolol and honokiol from Magnolia officinalis on Alternaria alternata causing Tobacco Brown Spot. Molecules 24, 2140. doi:10.3390/molecules 24112140

Chen, Y. H., Huang, P. H., Lin, F. Y., Chen, W. C., Chen, Y. L., Yin, W. H., et al. (2011). Magnolol: a multifunctional compound isolated from the Chinese medicinal plant Magnolia officinalis. Eur. J. Integr. Med. 3, e317-e324. doi:10.1016/j.eujim.2011.09.002

Cheng, G., Hardy, M., Zielonka, J., Weh, K., Zielonka, M., Boyle, K. A., et al. (2020). Mitochondria-targeted magnolol inhibits OXPHOS, proliferation, and tumor growth via modulation of energetics and autophagy in melanoma cells. Cancer Treat. Res. Commun. 25, 100210. doi:10.1016/j. ctarc.2020.100210

Cheng, J., Dong, S., Yi, L., Geng, D., and Liu, Q. (2018). Magnolol abrogates chronic mild stress-induced depressive-like behaviors by inhibiting neuroinflammation and oxidative stress in the prefrontal cortex of mice. Int. Immunopharmacol. 59, 61-67. doi:10.1016/j.intimp.2018.03.031

Cheng, Y. C., Hueng, D. Y., Huang, H. Y., Chen, J. Y., and Chen, Y. (2016). Magnolol and honokiol exert a synergistic anti-tumor effect through autophagy and apoptosis in human glioblastomas. Oncotarget 7, 29116-29130. doi:10. 18632/oncotarget.8674

Chicca, A., Gachet, M. S., Petrucci, V., Schuehly, W., Charles, R. P., and Gertsch, J. (2015). 4'-O-methylhonokiol increases levels of 2-arachidonoyl glycerol in mouse brain via selective inhibition of its COX-2-mediated oxygenation. J. Neuroinflammation 12, 89. doi:10.1186/s12974-015-0307-7

Chiu, K. C., Shih, Y. H., Wang, T. H., Lan, W. C., Li, P. J., Jhuang, H. S., et al. (2020). In vitro antimicrobial and antipro-inflammation potential of honokiol and magnolol against oral pathogens and macrophages. J. Formos. Med. Assoc. 120, 827-837. doi:10.1016/j.jfma.2020.09.002

Choi, E. J., Kim, H. I., Kim, J. A., Jun, S. Y., Kang, S. H., Park, D. J., et al. (2015). The herbal-derived honokiol and magnolol enhances immune response to infection with methicillin-sensitive Staphylococcus aureus (MSSA) and methicillinresistant S. aureus (MRSA). Appl. Microbiol. Biotechnol. 99, 4387-4396. doi:10.1007/s00253-015-6382-y

Choi, S. S., Cha, B. Y., Lee, Y. S., Yonezawa, T., Teruya, T., Nagai, K., et al. (2012). Honokiol and magnolol stimulate glucose uptake by activating PI3K-dependent Akt in L6 myotubes. BioFactors 38, 372-377. doi:10.1002/biof.1029

Chuang, T. C., Hsu, S. C., Cheng, Y. T., Shao, W. S., Wu, K., Fang, G. S., et al. (2011). Magnolol down-regulates HER2 gene expression, leading to inhibition of HER2-mediated metastatic potential in ovarian cancer cells. Cancer Lett. 311, 11-19. doi:10.1016/j.canlet.2011.06.007

Coppola, M., and Mondola, R. (2014). Potential use of Magnolia officinalis bark polyphenols in the treatment of cannabis dependence. Med. Hypotheses 83, 673-676. doi:10.1016/j.mehy.2014.09.015

Deng, Y., Han, X., Tang, S., Xiao, W., Tan, Z., Zhou, C., et al. (2015). Magnolol and honokiol regulate the calcium-activated potassium channels signaling pathway in Enterotoxigenic Escherichia coli-induced diarrhea mice. Eur. J. Pharmacol. 755, 66-73. doi:10.1016/j.ejphar.2015.03.002

Ding, P., Shen, H., Wang, J., and Ju, J. (2018). Improved oral bioavailability of magnolol by using a binary mixed micelle system. Artif. Cells Nanomed. Biotechnol. 46, 668-674. doi:10.1080/21691401.2018.1468339

Dong, J., Ding, H., Liu, Y., Yang, Q., Xu, N., Yang, Y., et al. (2017). Magnolol protects channel catfish from Aeromonas hydrophila infection via inhibiting the expression of aerolysin. Vet. Microbiol. 211, 119-123. doi:10.1016/j.vetmic. 2017.10.005

Dong, L., Zhou, S., Yang, X., Chen, Q., He, Y., and Huang, W. (2013). Magnolol protects against oxidative stress-mediated neural cell damage by modulating mitochondrial dysfunction and PI3K/Akt signaling. J. Mol. Neurosci. 50, 469-481. doi:10.1007/s12031-013-9964-0

Dreier, D., Latkolik, S., Rycek, L., Schnürch, M., Dymáková, A., Atanasov, A. G., et al. (2017). Linked magnolol dimer as a selective PPAR $\gamma$ agonist - structurebased rational design, synthesis, and bioactivity evaluation. Sci. Rep. 7, 13002. doi:10.1038/s41598-017-12628-5

Duan, J., Xiao, J., Chen, Y., and Han, F. (2015). Inhibition of magnolol and honokiol on cytochrome P450 enzymes in rat and human liver microsomes. Chin. Herb. Med. 7, 167-172. doi:10.1016/s1674-6384(15)60034-x 
Emran, A. Al., Chinna Chowdary, B. R., Ahmed, F., Hammerlindl, H., Huefner, A., Haass, N. K., et al. (2019). Magnolol induces cell death through PI3K/Akt-mediated epigenetic modifications boosting treatment of BRAF- and NRAS-mutant melanoma. Cancer Med. 8, 1186-1196. doi:10. $1002 / \mathrm{cam} 4.1978$

Erdtman, H., and Runeberg, J. (1957). Phenol dehydrogenations VII. Dehydrogenation of chavicol to magnolol. 6, 1060-1061. doi:10.3891/acta. chem.scand.11-1060

Fried, L. E., and Arbiser, J. L. (2009). Honokiol, a multifunctional antiangiogenic and antitumor agent. Antioxid. Redox Signal 11, 1139-1148. doi:10.1089/ars. 2009.2440

Fu, Y., Liu, B., Zhang, N., Liu, Z., Liang, D., Li, F., et al. (2013). Magnolol inhibits lipopolysaccharide-induced inflammatory response by interfering with TLR4 mediated NF- $\mathrm{kB}$ and MAPKs signaling pathways. J. Ethnopharmacol. 145, 193-199. doi:10.1016/j.jep.2012.10.051

Fuchs, A., Baur, R., Schoeder, C., Sigel, E., and Müller, C. E. (2014). Structural analogues of the natural products magnolol and honokiol as potent allosteric potentiators of GABAA receptors. Bioorg. Med. Chem. 22, 6908-6917. doi:10. 1016/j.bmc.2014.10.027

Fuchs, A., Rempel, V., and Müller, C. E. (2013). The natural product magnolol as a lead structure for the development of potent cannabinoid receptor agonists. PLoS One 8, e77739. doi:10.1371/journal.pone.0077739

Fujita, S., and Taira, J. (1994). Biphenyl compounds are hydroxyl radical scavengers: their effective inhibition for UV-induced mutation in Salmonella typhimurium TA102. Free Radic. Biol. Med. 17, 273-277. doi:10.1016/08915849(94)90083-3

Geiger, S., Nickl, K., Schneider, E. H., Seifert, R., and Heilmann, J. (2010). Establishment of recombinant cannabinoid receptor assays and characterization of several natural and synthetic ligands. Naunyn. Schmiedebergs. Arch. Pharmacol. 382, 177-191. doi:10.1007/s00210-0100534-5

Gong, C. L., Wong, K. L., Cheng, K. S., Kuo, C. S., Chao, C. C., Tsai, M. F., et al. (2012). Inhibitory effects of magnolol on voltage-gated $\mathrm{Na}+$ and $\mathrm{K}+$ channels of NG108-15 cells. Eur. J. Pharmacol. 682, 73-78. doi:10.1016/j.ejphar.2012. 02.013

Hagiwara, K., Gailhouste, L., Yasukawa, K., Kosaka, N., and Ochiya, T. (2015). A robust screening method for dietary agents that activate tumour-suppressor microRNAs. Sci. Rep. 5, 14697. doi:10.1038/srep14697

Han, H. K., and Van Anh, L. T. (2012). Modulation of P-glycoprotein expression by honokiol, magnololand 4-O-methylhonokiol, the bioactive components of Magnolia officinalis. Anticancer Res. 32, 4445-4452. doi:10.1016/j.soc.2012. 07.009

Hattori, M., Yoshiyuki, E., Takebe, S., Kobashi, K., Fukasaku, N., and Namba, T. (1986). Metabolism of magnolol from Magnoliae cortex. II. Absorption, metabolism and excretion of [ring-14C]magnolol in rats. Chem. Pharm. Bull. 34, 158-167. doi:10.1248/cpb.34.158

Hsieh, S. F., Chou, C. T., Liang, W. Z., Kuo, C. C., Wang, J. L., Hao, L. J., et al. (2018). The effect of magnolol on $\mathrm{Ca} 2+$ homeostasis and its related physiology in human oral cancer cells. Arch. Oral Biol. 89, 49-54. doi:10.1016/j.archoralbio. 2018.02.006

Huang, Y., Liu, C., Liu, S., Liu, Z., Li, S., and Wang, Y. (2019). In vitro metabolism of magnolol and honokiol in rat liver microsomes and their interactions with seven cytochrome P substrates. Rapid Commun. Mass. Spectrom. 33, 229-238. doi:10.1002/rcm.8314

Hwang, Y. H., Kim, T., Kim, R., and Ha, H. (2018). Magnolol inhibits osteoclast differentiation via suppression of RANKL expression. Molecules 23, 1598. doi: $10.3390 /$ molecules 23071598

Im, A. R., Song, J. H., Lee, M. Y., and Chae, S. (2015). Magnolol reduces UVB-induced photodamage by regulating matrix metalloproteinase activity. Environ. Toxicol. Pharmacol. 39, 417-423. doi:10.1016/j.etap. 2014.12.001

Joo, J., and Liu, K. H. (2013). Inhibitory effect of honokiol and magnolol on cytochrome P450 enzyme activities in human liver microsomes. Mass Spectrom. Lett. 4, 34-37. doi:10.5478/MSL.2013.4.1.34

Kang, Y. J., Park, H. J., Chung, H. J., Min, H. Y., Park, E. J., Lee, M. A., et al. (2012). Wnt/ $\beta$-catenin signaling mediates the antitumor activity of magnolol in colorectal cancer cells. Mol. Pharmacol. 82, 168-177. doi:10.1124/mol.112.078535
Karki, R., Ho, O. M., and Kim, D. W. (2013a). Magnolol attenuates neointima formation by inducing cell cycle arrest via inhibition of ERK1/2 and NF-kB activation in vascular smooth muscle cells. Biochim. Biophys. Acta - Gen. Subj. 1830, 2619-2628. doi:10.1016/j.bbagen.2012.12.015

Karki, R., Jeon, E. R., and Kim, D. W. (2012). Magnoliae Cortex inhibits intimal thickening of carotid artery through modulation of proliferation and migration of vascular smooth muscle cells. Food Chem. Toxicol. 50, 634-640. doi:10.1016/ j.fct.2011.11.043

Karki, R., Kim, S. B., and Kim, D. W. (2013b). Magnolol inhibits migration of vascular smooth muscle cells via cytoskeletal remodeling pathway to attenuate neointima formation. Exp. Cell Res. 319, 3238-3250. doi:10.1016/j.yexcr.2013. 07.016

Kaushik, G., Venugopal, A., Ramamoorthy, P., Standing, D., Subramaniam, D., Umar, S., et al. (2015). Honokiol inhibits melanoma stem cells by targeting notch signaling. Mol. Carcinog. 54, 1710-1721. doi:10.1002/mc.22242

Kim, A., Lee, S. Y., Seo, C. S., and Chung, S. K. (2020). Ethanol extract of Magnoliae cortex (EEMC) limits teratoma formation of pluripotent stem cells by selective elimination of undifferentiated cells through the p53-dependent mitochondrial apoptotic pathway. Phytomedicine 69, 153198. doi:10.1016/j.phymed.2020.153198

Kim, D. J., and Kim, Y. S. (2016). Magnolol protects against trimethyltin-induced neuronal damage and glial activation in vitro and in vivo. Neurotoxicology 53 , 173-185. doi:10.1016/j.neuro.2016.01.001

Kim, G. D., Oh, J., Park, H. J., Bae, K., and Lee, S. K. (2013). Magnolol inhibits angiogenesis by regulating ROS-mediated apoptosis and the PI3K/AKT/mTOR signaling pathway in $\mathrm{mES} / \mathrm{EB}$-derived endothelial-like cells. Int. J. Oncol. 43, 600-610. doi:10.3892/ijo.2013.1959

Kim, H. J., Han, T., Kim, Y. T., So, I., and Kim, B. J. (2018). Magnolia officinalis bark extract induces depolarization of pacemaker potentials through $\mathrm{M} 2$ and $\mathrm{M}$ 3 muscarinic receptors in cultured murine small intestine interstitial cells of cajal. Cell. Physiol. Biochem. 43, 1790-1802. doi:10.1159/000484065

Kim, J. Y., Kim, K. H., Kwag, E. H., Seol, Y. J., Lee, Y. M., Ku, Y., et al. (2018). Magnoliae Cortex and maize modulate Porphyromonas gingivalis-induced inflammatory reactions. J. Periodontal Implant Sci. 48, 70-83. doi:10.5051/ jpis.2018.48.2.70

Kim, S. B., Kang, H. E., Cho, H. J., Kim, Y. S., Chung, S. J., Yoon, I. S., et al. (2015). Metabolic interactions of magnolol with cytochrome P450 enzymes: uncompetitive inhibition of CYP1A and competitive inhibition of CYP2C. Drug Dev. Ind. Pharm. 42, 263-269. doi:10.3109/03639045.2015.1047846

Kim, S. B., Kim, K. S., Ryu, H. M., Hong, S. H., Kim, B. K., Kim, D. D., et al. (2018). Modulation of rat hepatic CYP1A and 2C activity by honokiol and magnolol: differential effects on phenacetin and diclofenac pharmacokinetics in vivo. Molecules 23, 1470. doi:10.3390/molecules23061470

Kim, S. Y., Kim, J., Jeong, S. Il., Jahng, K. Y., and Yu, K. Y. (2015). Antimicrobial effects and resistant regulation of magnolol and honokiol on methicillinresistant Staphylococcus aureus. Biomed. Res. Int. 2015, 283630. doi:10.1155/ 2015/283630

Kim, Y. J., Choi, M. S., Cha, B. Y., Woo, J. T., Park, Y. B., Kim, S. R., et al. (2013). Long-term supplementation of honokiol and magnolol ameliorates body fat accumulation, insulin resistance, and adipose inflammation in high-fat fed mice. Mol. Nutr. Food Res. 57, 1988-1998. doi:10.1002/mnfr.201300113

Kou, D. Q., Jiang, Y. L., Qin, J. H., and Huang, Y. H. (2017). Magnolol attenuates the inflammation and apoptosis through the activation of SIRT1 in experimental stroke rats. Pharmacol. Rep. 69, 642-647. doi:10.1016/j.pharep. 2016.12.012

Kuk, H., Arnold, C., Meyer, R., Hecker, M., and Korff, T. (2017). Magnolol inhibits venous remodeling in mice. Sci. Rep. 7, 17820. doi:10.1038/s41598-017-17910-0

Kuo, D. H., Tsai, S. W., and Pan, M. H. (2011). Magnolol blocks homocysteineinduced endothelial dysfunction in porcine coronary arteries. Food Chem. 127, 135-140. doi:10.1016/j.foodchem.2010.12.101

Kwak, E. J., Lee, Y. S., and Choi, E. M. (2012). Effect of magnolol on the function of osteoblastic MC3T3-E1 cells. Mediators Inflamm. 2012, 829650. doi:10.1155/ 2012/829650

Łata, E., Fulczyk, A., Ott, P. G., Kowalska, T., Sajewicz, M., and Móricz, Á. M. (2020). Thin-layer chromatographic quantification of magnolol and honokiol in dietary supplements and selected biological properties of these preparations. J. Chromatogr. A. 1625, 461230. doi:10.1016/j.chroma.2020.461230

Lai, C. S., Lai, Y. S., Kuo, D. H., Wu, C. H., Ho, C. T., and Pan, M. H. (2011). Magnolol potently suppressed lipopolysaccharide-induced iNOS and COX-2 
expression via downregulating MAPK and NF- $\mathrm{BB}$ signaling pathways. J. Funct. Foods 3, 198-206. doi:10.1016/j.jff.2011.04.002

Lee, J. S., Sul, J. Y., Park, J. B., Lee, M. S., Cha, E. Y., and Ko, Y. B. (2019). Honokiol induces apoptosis and suppresses migration and invasion of ovarian carcinoma cells via AMPK/mTOR signaling pathway. Int. J. Mol. Med. 43, 1969-1978. doi:10.3892/ijmm.2019.4122

Lee, W. T., Lin, M. H., Lee, E. J., Hung, Y. C., Tai, S. H., Chen, H. Y., et al. (2012). Magnolol reduces glutamate-induced neuronal excitotoxicity and protects against permanent focal cerebral ischemia up to 4 hours. PLoS One 7, e39952. doi:10.1371/journal.pone.0039952

Lee, Y. J., Choi, D. Y., Yun, Y. P., Han, S. B., Kim, H. M., Lee, K., et al. (2013). Ethanol extract of magnolia officinalis prevents lipopolysaccharide-induced memory deficiency via its antineuroinflammatory and antiamyloidogenic effects. Phyther. Res. 27, 438-447. doi:10.1002/ptr.4740

Lee, Y. K., Yuk, D. Y., Kim, T. Il., Kim, Y. H., Kim, K. T., Kim, K. H., et al. (2009). Protective effect of the ethanol extract of Magnolia officinalis and 4-Omethylhonokiol on scopolamine-induced memory impairment and the inhibition of acetylcholinesterase activity. J. Nat. Med. 63, 274-282. doi:10. 1007/s11418-009-0330-z

Leeman-Neill, R. J., Cai, Q., Joyce, S. C., Thomas, S. M., Bhola, N. E., Neill, D. B., et al. (2010). Honokiol inhibits epidermal growth factor receptor signaling and enhances the antitumor effects of epidermal growth factor receptor inhibitors. Clin. Cancer Res. 16, 2571-2579. doi:10.1158/1078-0432.CCR-10-0333

Li, G., Lu, Y., Fan, Y., Ning, Q., and Li, W. (2020). Enhanced oral bioavailability of magnolol via mixed micelles and nanosuspensions based on Soluplus ${ }^{\circledR}$ Poloxamer 188. Drug Deliv. 27, 1010-1017. doi:10.1080/10717544.2020. 1785582

Li, J., Copmans, D., Partoens, M., Hunyadi, B., Luyten, W., and De Witte, P. (2020). Zebrafish-based screening of antiseizure plants used in traditional Chinese medicine: Magnolia officinalis extract and its constituents magnolol and honokiol exhibit potent anticonvulsant activity in a therapy-resistant epilepsy model. ACS Chem. Neurosci. 11, 730-742. doi:10.1021/ acschemneuro. $9 \mathrm{~b} 00610$

Li, J., Meng, A. P., Guan, X. L., Li, J., Wu, Q., Deng, S. P., et al. (2013). Anti-hepatitis $\mathrm{B}$ virus lignans from the root of Streblus asper. Bioorg. Med. Chem. Lett. 23, 2238-2244. doi:10.1016/j.bmcl.2013.01.046

Li, J., Yang, J. H., Jiang, Z. T., Han, Y., Di, L. Q., and Liu, C. (2019). Preparation and bioavailability of magnolol solid dispersions. Chin. Tradit. Herb. Drugs 50, 3337-3344. doi:10.7501/j.issn.0253-2670.2019.14.011

Li, L. F., Lu, J., Li, X. M., Xu, C. L., Deng, J. M., Qu, R., et al. (2012). Anect of magnolol on BDNF up-regulation and serotonergic system activity in unpredictable chronic mild stress treated rats. Phyther. Res. 26, 1189-1194. doi:10.1002/ptr.3706

Li, L. F., Yang, J., Ma, S. P., and Qu, R. (2013). Magnolol treatment reversed the glial pathology in an unpredictable chronic mild stress-induced rat model of depression. Eur. J. Pharmacol. 711, 42-49. doi:10.1016/j.ejphar.2013.04.008

Li, M., Zhang, F., Wang, X., Wu, X., Zhang, B., Zhang, N., et al. (2015). Magnolol inhibits growth of gallbladder cancer cells through the p53 pathway. Cancer Sci. 106, 1341-1350. doi:10.1111/cas.12762

Li, N., Song, Y., Zhang, W., Wang, W., Chen, J., Wong, A. W., et al. (2007). Evaluation of the in vitro and in vivo genotoxicity of magnolia bark extract. Regul. Toxicol. Pharmacol. 49, 154-159. doi:10.1016/j.yrtph.2007.06.005

Liang, C. J., Lee, C. W., Sung, H. C., Chen, Y. H., Wang, S. H., Wu, P. J., et al. (2014). Magnolol reduced TNF- $\alpha$-induced vascular cell adhesion molecule-1 expression in endothelial cells via JNK/p38 and NF- $\mathrm{\kappa B}$ signaling pathways. Am. J. Chin. Med. 42, 619-637. doi:10.1142/S0192415X14500402

Liang, X., Xing, W., He, J., Liu, F., Gao, F., and Zhang, H. (2014). GW25-e4408 Magnolol administration in prehypertension postpones the development of hypertension and the underlying mechanisms. J. Am. Coll. Cardiol. 64, C25. doi:10.1016/j.jacc.2014.06.123

Lin, C. J., Chen, T. L., Tseng, Y. Y., Wu, G. J., Hsieh, M. H., Lin, Y. W., et al. (2016). Honokiol induces autophagic cell death in malignant glioma through reactive oxygen species-mediated regulation of the p53/PI3K/Akt/mTOR signaling pathway. Toxicol. Appl. Pharmacol. 304, 59-69. doi:10.1016/j.taap.2016.05.018

Lin, M. H., Chen, M. C., Chen, T. H., Chang, H. Y., and Chou, T. C. (2015). Magnolol ameliorates lipopolysaccharide-induced acute lung injury in rats through PPAR- $\gamma$-dependent inhibition of NF-kB activation. Int. Immunopharmacol. 28, 270-278. doi:10.1016/j.intimp.2015.05.051
Lin, S. P., Hou, Y. C., Liao, T. Y., and Tsai, S. Y. (2014). Enhancing the bioavailability of magnolol in rabbits using melting solid dispersion with polyvinylpyrrolidone. Drug Dev. Ind. Pharm. 40, 330-337. doi:10.3109/ 03639045.2012.760580

Lin, S. P., Tsai, S. Y., Lee Chao, P. D., Chen, Y. C., and Hou, Y. C. (2011). Pharmacokinetics, bioavailability, and tissue distribution of magnolol following single and repeated dosing of magnolol to rats. Planta Med. 77, 1800-1805. doi:10.1055/s-0030-1271159

Liu, C., Zhi, W., Ren, J., Zhang, P., and Gao, N. (2016). In Vitro inhibitory effects of honokiol, magnolol, geniposide, chlorogenic acid, and astragaloside IV on CYP1A2, CYP3A and CYP2D activity in human and rats. Chin. J. Mod. Pharm. 33, 871-875. doi:10.13748/j.cnki.issn1007-7693.2016.07.009

Liu, H. Z., Dong, D. D., and Fan, M. S. (2020). Different preparations of magnolol: preparation, characterization and pharmacokinetics comparative study in SD rats. Chin. Tradit. Herb. Drugs 51, 4442-4448. doi:10.7501/j.issn.0253-2670.2020.17.011

Liu, S. H., Wang, K. B., Lan, K. H., Lee, W. J., Pan, H. C., Wu, S. M., et al. (2012). Calpain/SHP-1 interaction by honokiol dampening peritoneal dissemination of gastric cancer in nu/nu mice. PLoS One 7, e43711. doi:10.1371/journal.pone. 0043711

Liu, T., Pan, Y., and Lai, R. (2014). New mechanism of magnolol and honokiol from Magnolia officinalis against Staphylococcus aureus. Nat. Prod. Commun. 9, 1307-1309. doi:10.1177/1934578x1400900922

Liu, X., Chen, X., Zhu, Y., Wang, K., and Wang, Y. (2017). Effect of magnolol on cerebral injury and blood brain barrier dysfunction induced by ischemiareperfusion in vivo and in vitro. Metab. Brain Dis. 32, 1109-1118. doi:10. 1007/s11011-017-0004-6

Liu, Y., Cao, W., Zhang, B., Liu, Y. Q., Wang, Z. Y., Wu, Y. P., et al. (2013). The natural compound magnolol inhibits invasion and exhibits potential in human breast cancer therapy. Sci. Rep. 3, 3098. doi:10.1038/srep03098

Lu, S. H., Chen, T. H., and Chou, T. C. (2015a). Magnolol inhibits RANKL-induced osteoclast differentiation of RAW 264.7 macrophages through heme oxygenase-1-dependent inhibition of NFATc1 expression. J. Nat. Prod. 78, 61-68. doi:10.1021/np500663y

Lu, S. H., Hsu, W. L., Chen, T. H., and Chou, T. C. (2015b). Activation of Nrf2/HO1signaling pathway involves the anti-inflammatory activity of magnolol in Porphyromonas gingivalis lipopolysaccharide-stimulated mouse RAW 264.7 macrophages. Int. Immunopharmacol. 29, 770-778. doi:10.1016/j.intimp.2015. 08.042

Lu, S. H., Huang, R. Y., and Chou, T. C. (2013). Magnolol ameliorates ligatureinduced periodontitis in rats and osteoclastogenesis: in vivo and in vitro study. Evid.-Based Complement Altern. Med. 2013, 634095. doi:10.1155/2013/634095

Luo, J., Xu, Y., Zhang, M., Gao, L., Fang, C., and Zhou, C. (2013). Magnolol inhibits LPS-induced inflammatory response in uterine epithelial cells. Inflammation 36, 997-1003. doi:10.1007/s10753-013-9631-1

Maddaloni, E., Moretti, C., Mignogna, C., and Buzzetti, R. (2020). Adult-onset autoimmune diabetes in 2020: an update. Maturitas 137, 37-44. doi:10.1016/j. maturitas.2020.04.014

Matsui, N., Akae, H., Hirashima, N., Kido, Y., Tanabe, S., Koseki, M., et al. (2016). Magnolol enhances hippocampal neurogenesis and exerts antidepressant-like effects in olfactory bulbectomized mice. Phyther. Res. 30, 1856-1861. doi:10.1002/ptr.5695

McKeown, B. T., and Hurta, R. A. R. (2015). Magnolol affects cellular proliferation, polyamine biosynthesis and catabolism-linked protein expression and associated cellular signaling pathways in human prostate cancer cells in vitro. Funct. Foods Heal. Dis. 5, 17-33. doi:10.31989/ffhd.v5i1.163

McKeown, B. T., and Hurta, R. A. R. (2014). Magnolol affects expression of IGF-1 and associated binding proteins in human prostate cancer cells in vitro. Anticancer Res. 34, 6333-6338.

McKeown, B. T., McDougall, L., Catalli, A., and Hurta, R. A. R. (2014). Magnolol causes alterations in the cell cycle in androgen insensitive human prostate cancer cells in vitro by affecting expression of key cell cycle regulatory proteins. Nutr. Cancer 66, 1154-1164. doi:10.1080/ 01635581.2014 .951736

Niu, X., Cheng, L., and Li, Q. (2015). The absorption of magnolol and honokiol in different intestinal tracts of rats and their relationship with drug concentration. J. Chin. Med. Mater. 38, 817-820. doi:10.13863/j.issn1001-4454.2015.04.042

Ochiuz, L., Hortolomei, M., Stoleriu, I., and Bercea, M. (2016). Dermatocosmetics based on hydroxypropyl cellulose for acne treatment. Rheological and drug delivery behaviour. Cellul. Chem. Technol. 50, 569-575. 
Ong, C. P., Lee, W. L., Tang, Y. Q., and Yap, W. H. (2020). Honokiol: a review of its anticancer potential and mechanisms. Cancers 12, 48. doi:10.3390/ cancers 12010048

Onoda, T., Li, W., Sasaki, T., Miyake, M., Higai, K., and Koike, K. (2016). Identification and evaluation of magnolol and chrysophanol as the principle protein tyrosine phosphatase-1B inhibitory compounds in a Kampo medicine, Masiningan. J. Ethnopharmacol. 186, 84-90. doi:10.1016/j.jep.2016.03.063

Oufensou, S., Scherm, B., Pani, G., Balmas, V., Fabbri, D., Dettori, M. A., et al. (2019). Honokiol, magnolol and its monoacetyl derivative show strong antifungal effect on Fusarium isolates of clinical relevance. PLoS One 14, e0221249. doi:10.1371/journal.pone.0221249

Pang, Y. L., Han, X. F., Bamikole, M. A., Gong, Z. H., Tang, S. X., Tan, Z. L., et al. (2013). Anti-diarrhea and anti-oxidant properties of magnolol. Trop. J. Pharm. Res. 12, 85-91. doi:10.4314/tjpr.v12i1.14

Park, J. B., Lee, M. S., Cha, E. Y., Lee, J. S., Sul, J. Y., Song, I. S., et al. (2012). Magnolol-induced apoptosis in HCT-116 colon cancer cells is associated with the AMP-activated protein kinase signaling pathway. Biol. Pharm. Bull. 35, 1614-1620. doi:10.1248/bpb.b12-00352

Parray, H. A., Lone, J., Park, J. P., Choi, J. W., and Yun, J. W. (2018). Magnolol promotes thermogenesis and attenuates oxidative stress in 3T3-L1 adipocytes. Nutrition 50, 82-90. doi:10.1016/j.nut.2018.01.017

Piasecka, D., Braun, M., Mieszkowska, M., Kowalczyk, L., Kopczynski, J., Kordek, R., et al. (2020). Upregulation of HIF1- $\alpha$ via an NF-kB/COX2 pathway confers proliferative dominance of HER2-negative ductal carcinoma in situ cells in response to inflammatory stimuli. Neoplasia 22, 576-589. doi:10.1016/j.neo. 2020.09.003

Pulvirenti, L., Muccilli, V., Cardullo, N., Spatafora, C., and Tringali, C. (2017). Chemoenzymatic synthesis and $\alpha$-glucosidase inhibitory activity of dimeric neolignans inspired by magnolol. J. Nat. Prod. 80, 1648-1657. doi:10.1021/acs. jnatprod.7b00250

Qiu, N., Shen, B., Li, X., Zhang, X., Sang, Z., Yang, T., et al. (2016). Inclusion complex of magnolol with hydroxypropyl- $\beta$-cyclodextrin: characterization, solubility, stability and cell viability. J. Incl. Phenom. Macrocycl. Chem. 85, 289-301. doi:10.1007/s10847-016-0628-x

Ranaware, A. M., Banik, K., Deshpande, V., Padmavathi, G., Roy, N. K., Sethi, G., et al. (2018). Magnolol: a neolignan from the Magnolia family for the prevention and treatment of cancer. Int. J. Mol. Sci. 19, 2362. doi:10.3390/ ijms19082362

Rasul, A., Yu, B., Khan, M., Zhang, K., Iqbal, F., Ma, T., et al. (2012). Magnolol, a natural compound, induces apoptosis of SGC-7901 human gastric adenocarcinoma cells via the mitochondrial and PI3K/Akt signaling pathways. Int. J. Oncol. 40, 1153-1161. doi:10.3892/ijo.2011.1277

Rauf, A., Patel, S., Imran, M., Maalik, A., Arshad, M. U., Saeed, F., et al. (2018). Honokiol: an anticancer lignan. Biomed. Pharmacother. 107, 555-562. doi:10. 1016/j.biopha.2018.08.054

Rempel, V., Fuchs, A., Hinz, S., Karcz, T., Lehr, M., Koetter, U., et al. (2013). Magnolia extract, magnolol, and metabolites: activation of cannabinoid CB2 receptors and blockade of the related GPR55. ACS Med. Chem. Lett. 4 (1), 41-45. doi:10.1021/ml300235q

Rycek, L., Puthenkalam, R., Schnürch, M., Ernst, M., and Mihovilovic, M. D. (2015). Metal-assisted synthesis of unsymmetrical magnolol and honokiol analogs and their biological assessment as GABAA receptor ligands. Bioorg. Med. Chem. Lett. 25, 400-403. doi:10.1016/j.bmcl.2014.10.091

Saito, J., Sakai, Y., and Nagase, H. (2006). In vitro anti-mutagenic effect of magnolol against direct and indirect mutagens. Mutat. Res. - Genet. Toxicol. Environ. Mutagen. 609, 68-73. doi:10.1016/j.mrgentox.2006.06.021

Sakaue, Y., Domon, H., Oda, M., Takenaka, S., Kubo, M., Fukuyama, Y., et al. (2016). Anti-biofilm and bactericidal effects of magnolia bark-derived magnolol and honokiol on Streptococcus mutans. Microbiol. Immunol. 60, 10-16. doi:10. $1111 / 1348-0421.12343$

Santos, J. H., Quimque, M. T. J., Macabeo, A. P. G., Corpuz, M. J. A. T., Wang, Y. M., Lu, T. T., et al. (2020). Enhanced oral bioavailability of the pharmacologically active lignin magnolol via Zr-based metal organic framework impregnation. Pharmaceutics 12, 437. doi:10.3390/ pharmaceutics 12050437

Sarrica, A., Kirika, N., Romeo, M., Salmona, M., and Diomede, L. (2018). Safety and toxicology of magnolol and honokiol. Planta Med. 84, 1151-1164. doi:10.1055/ a-0642-1966
Schuehly, W., Paredes, J. M. V., Kleyer, J., Huefner, A., Anavi-Goffer, S., Raduner S., et al. (2011). Mechanisms of osteoclastogenesis inhibition by a novel class of biphenyl-type cannabinoid CB 2 receptor inverse agonists. Chem. Biol. 18, 1053-1064. doi:10.1016/j.chembiol.2011.05.012

Seo, J. U., Kim, M. H., Kim, H. M., and Jeong, H. J. (2011). Anticancer potential of magnolol for lung cancer treatment. Arch. Pharm. Res. 34, 625-633. doi:10. 1007/s12272-011-0413-8

Shen, B. L. S., An, L. Y., Qiu, N., Luo, L. N., and Cai, B. J. (2016). Preparation and characterization of magnolol liposomes. Lishizhen Med. Mat. Med. Res. 27, 1647-1650.

Shen, H.Liu, S., Ding, P., Wang, L., Ju, J., and Liang, G. (2018). Enhancement of oral bioavailability of magnolol by encapsulation in mixed micelles containing pluronic F127 and L61. J. Pharm. Pharmacol. 70, 498-506. doi:10.1111/jphp. 12887

Shen, J. L., Man, K. M., Huang, P. H., Chen, W. C., Chen, D. C., Cheng, Y. W., et al. (2010). Honokiol and magnolol as multifunctional antioxidative molecules for dermatologic disorders. Molecules 15, 6452-6465. doi:10.3390/ molecules15096452

Shen, J., Ma, H., Zhang, T., Liu, H., Yu, L., Li, G., et al. (2017). Magnolol inhibits the growth of non-small cell lung cancer via inhibiting microtubule polymerization. Cell. Physiol. Biochem. 42, 1789-1801. doi:10.1159/000479458

Shen, P.Zhang, Z., He, Y., Gu, C., Zhu, K., Li, S., et al. (2018). Magnolol treatment attenuates dextran sulphate sodium-induced murine experimental colitis by regulating inflammation and mucosal damage. Life Sci. 196, 69-76. doi:10.1016/ j.lfs.2018.01.016

Sheng, Y. L., Xu, J. H., Shi, C. H., Li, W., Xu, H. Y., Li, N., et al. (2014). UPLC-MS/ MS-ESI assay for simultaneous determination of magnolol and honokiol in rat plasma: application to pharmacokinetic study after administration emulsion of the isomer. J. Ethnopharmacol. 155, 1568-1574. doi:10.1016/j.jep.2014.07.052

Shih, C. Y., and Chou, T. C. (2012). The antiplatelet activity of magnolol is mediated by PPAR- $\beta / \gamma$. Biochem. Pharmacol. 84, 793-803. doi:10.1016/j.bcp.2012.06.022

Shih, H. C., Huang, M. S., and Lee, C. H. (2012). Magnolol attenuates the lung injury in hypertonic saline treatment from mesenteric ischemia reperfusion through diminishing iNOS. J. Surg. Res. 175, 305-311. doi:10.1016/j.jss.2011.04.063

Song, C., Song, K., Wu, X., Tu, X., Qi, X., Wang, G., et al. (2018). Antiparasitic efficacy and safety assessment of magnolol against Ichthyophthirius multifiliis in goldfish. Aquaculture 486, 9-17. doi:10.1016/j.aquaculture.2017.12.002

Stefanache, A., Ignat, M., Peptu, C. A., Diaconu, A., Stoleriu, I., and Ochiuz, L. (2017a). Development of a prolonged-release drug delivery system with magnolol loaded in amino-functionalized mesoporous silica. Appl. Sci. 7, 237. doi:10.3390/app7030237

Stefanache, A., Tantnru, G., Ignat, M., Creteanu, A., and Ochiuz, L. (2017b). Development of mesoporou silicate nanoparticles as drug carrier for magnolol. Sect. Micro Nano Teachnologies 17, 111.

Suh, K. S., Chon, S., Jung, W. W., and Choi, E. M. (2017). Magnolol protects pancreatic $\beta$-cells against methylglyoxal-induced cellular dysfunction. Chem. Biol. Interact. 277, 101-109. doi:10.1016/j.cbi.2017.09.014

Talarek, S., Listos, J., Barreca, D., Tellone, E., Sureda, A., Nabavi, S. F., et al. (2017). Neuroprotective effects of honokiol: from chemistry to medicine. BioFactors 43 , 760-769. doi:10.1002/biof.1385

Tang, L., Qiu, S. B., Wu, L., Lv, L. F., Lv, H. X., and Shan, W. G. (2016). Preparation and in vitro dissolution of magnolol solid dispersion. China J. Chin. Mater. Med. 41, 433-437. doi:10.4268/cjcmm20160312

Totah, R. A., and Rettie, A. E. (2005). Cytochrome P450 2C8: substrates, inhibitors, pharmacogenetics, and clinical relevance. Clin. Pharmacol. Ther. 77, 341-352. doi:10.1016/j.clpt.2004.12.267

Tsai, T. H., Chou, C. J., Lee, T. F., Wang, L. C. H., and Chen, C. F. (1996), Pharmacokinetic and pharmacodynamic studies of magnolol after oral administration in rats. Pharm. Sci. 2, 191-193. doi:10.1111/j.2042-7158.1996. tb00592.x

Tse, A. K. W., Wan, C. K., Shen, X. L., Yang, M., and Fong, W. F. (2005). Honokiol inhibits TNF- $\alpha$-stimulated NF- $\kappa B$ activation and NF- $\mathrm{kB}$-regulated gene expression through suppression of IKK activation. Biochem. Pharmacol. 70, 1443-1457. doi:10.1016/j.bcp.2005.08.011

Vavilala, D. T., Ponnaluri, V. K. C., Kanjilal, D., and Mukherji, M. (2014). Evaluation of anti-HIF and anti-angiogenic properties of honokiol for the treatment of ocular neovascular diseases. PLoS One 9, e113717. doi:10.1371/ journal.pone.0113717 
Wang, C. C., Lin, K. C., Lin, B. S., Chio, C. C., and Kuo, J. R. (2013). Resuscitation from experimental traumatic brain injury by magnolol therapy. J. Surg. Res. 184, 1045-1052. doi:10.1016/j.jss.2013.04.059

Wang, H. Y., Wang, J. S., Shan, S. M., Wang, X. B., Luo, J., Yang, M. H., et al. (2013). Chemical constituents from Trichilia connaroides and their nitric oxide production and a-glucosidase inhibitory activities. Planta Med. 79, 1767-1774. doi:10.1055/s-0033-1351045

Wang, J. H., Shih, K. S., Liou, J. P., Wu, Y. W., Chang, A. S. Y., Wang, K. L., et al. (2012). Anti-Arthritic effects of magnolol in human interleukin $1 \beta$-Stimulated Fibroblast-Like synoviocytes and in a rat arthritis model. PLoS One 7, e31368. doi:10.1371/journal.pone.0031368

Wang, L., Waltenberger, B., Pferschy-Wenzig, E. M., Blunder, M., Liu, X., Malainer, C., et al. (2014). Natural product agonists of peroxisome proliferator-activated receptor gamma (PPAR $\gamma)$ : a review. Biochem. Pharmacol. 92, 73-89. doi:10.1016/j.bcp.2014.07.018

Wang, Y. J., Chien, Y. C., Wu, C. H., and Liu, D. M. (2011). Magnololloaded core-shell hydrogel nanoparticles: drug release, intracellular uptake, and controlled cytotoxicity for the inhibition of migration of vascular smooth muscle cells. Mol. Pharm. 8, 2339-2349. doi:10.1021/ mp200257y

Wei, W., Dejie, L., Xiaojing, S., Tiancheng, W., Yongguo, C., Zhengtao, Y., et al. (2014). Magnolol inhibits the inflammatory response in mouse mammary epithelial cells and a mouse mastitis model. Inflammation 38, 16-26. doi:10. 1007/s10753-014-0003-2

Woodbury, A., Yu, S. P., Wei, L., and García, P. (2013). Neuro-modulating effects of honokiol: a review. Front. Neurol. 4, 130. doi:10.3389/fneur.2013. 00130

Wu, C., Wang, H., Xu, J., Huang, J., Chen, X., and Liu, G. (2014). Magnolol inhibits tumor necrosis factor- $\alpha$-induced ICAM-1 expression via suppressing NF- $\kappa B$ and MAPK signaling pathways in human lung epithelial cells. Inflammation 37, 1957-1967. doi:10.1007/s10753-014-9928-8

Wu, L., Zou, H., Xia, W., Dong, Q., and Wang, L. (2015). Rolle von Magnolol bei der Proliferation glatter Muskelzellen der Gefäße. Herz 40, 542-548. doi:10. 1007/s00059-014-4051-Z

Xie, Z., Zhao, J., Wang, H., Jiang, Y., Yang, Q., Fu, Y., et al. (2020). Magnolol alleviates Alzheimer's disease-like pathology in transgenic C. elegans by promoting microglia phagocytosis and the degradation of beta-amyloid through activation of PPAR- $\gamma$. Biomed. Pharmacother. 124, 109886. doi:10. 1016/j.biopha.2020.109886

Yang, B., Xu, Y., Yu, S., Huang, Y., Lu, L., and Liang, X. (2016). Antiangiogenic and anti-inflammatory effect of Magnolol in the oxygeninduced retinopathy model. Inflamm. Res. 65, 81-93. doi:10.1007/ s00011-015-0894-x

Zeng, H., Zhou, Q., Luo, T., and Liu, B. (2015). The effects of magnolol and honokiol on the inhibition of diarrhea and gastrointestinal drainage in mice were compared. J. Chin. Med. Mater. 38, 2160-2162. doi:10.13863/j.issn10014454.2015.10.035

Zhang, F. H., Ren, H. Y., Shen, J. X., Zhang, X. Y., Ye, H. M., and Shen, D. Y. (2017). Magnolol suppresses the proliferation and invasion of cholangiocarcinoma cells via inhibiting the NF- $\mathrm{KB}$ signaling pathway. Biomed. Pharmacother. 94, 474-480. doi:10.1016/j.biopha.2017.07.085

Zhang, L.Wang, J., Xu, W., Sun, Y., You, J., Lu, H., et al. (2018). Magnolol inhibits Streptococcus suis-induced inflammation and ROS formation via TLR2/MAPK/ NF-кB signaling in RAW264.7 cells. Pol. J. Vet. Sci. 21, 111-118. doi:10.24425/ 119028

Zhang, M., Zang, K. H., Luo, J. L., Leung, F. P., Huang, Y., Lin, C. Y., et al. (2013). Magnolol inhibits colonic motility through down-regulation of voltagesensitive L-type $\mathrm{Ca} 2+$ channels of colonic smooth muscle cells in rats. Phytomedicine 20, 1272-1279. doi:10.1016/j.phymed.2013.07.008

Zhang, P., Ren, J., Zhi, W., Liu, C., and Gao, N. (2017). Inhibition of CYP450 activity by honokiol and other four components of Chinese traditionalmedicine in vitro. Chin. J. Clin. Pharmacol. Ther. 22, 922-926.

Zhang, T.Ma, M., Liu, T., Cao, Z., and Xu, W. (2018). Effect of magnolol and honokiol on the activity of the drug-maetabolizing enzyme CYP2C19. J. Qingdao Univ. Med. Sci. 54, doi:10.11712/jms201806018

Zhang, Y., and Sun, P. (2011). Study on the improvement of combustion performance. Chem. Res. Appl. 23, 1574-1575. doi:10.1299/jsme1958.18.1061

Zhou, F., Jiang, Z., Yang, B., and Hu, Z. (2019). Magnolol exhibits antiinflammatory and neuroprotective effects in a rat model of intracerebral haemorrhage. Brain Behav. Immun. 77, 161-167. doi:10.1016/j.bbi.2018.12.018

Zhou, W., Lin, X., Chu, J., Jiang, T., Zhao, H., Yan, B., et al. (2019). Magnolol prevents ossified tendinopathy by inhibiting PGE2-induced osteogenic differentiation of TDSCs. Int. Immunopharmacol. 70, 117-124. doi:10.1016/j.intimp.2019.02.010

Zuo, G. Y., Zhang, X. J., Han, J., Li, Y. Q., and Wang, G. C. (2015). In vitro synergism of magnolol and honokiol in combination with antibacterial agents against clinical isolates of methicillin-resistant Staphylococcus aureus (MRSA). BMC Complement. Altern. Med. 15, 425. doi:10.1186/s12906-015-0938-3

Conflict of Interest: The authors declare that the research was conducted in the absence of any commercial or financial relationships that could be construed as a potential conflict of interest.

Copyright (C) $2021 \mathrm{Lin}, \mathrm{Li}$, Zeng, Tian, Qu, Yuan and Song. This is an open-access article distributed under the terms of the Creative Commons Attribution License (CC $B Y)$. The use, distribution or reproduction in other forums is permitted, provided the original author(s) and the copyright owner(s) are credited and that the original publication in this journal is cited, in accordance with accepted academic practice. No use, distribution or reproduction is permitted which does not comply with these terms. 


\section{GLOSSARY}

(iNOS) inducible nitric oxide synthase

(COX-2) cyclooxygenase-2

(NF-kB) nuclear factor- $\kappa \mathrm{B}$

(MAPK) mitogen-activated protein kinase

(PGEs) prostaglandins

(ERK) extracellular signal-regulated kinase

(BMK1) big mitogen-activated protein kinase 1

(SAPK) stress-activated protein kinase

(JNK) c-Jun N-terminal kinase

(NO) nitric oxidenitric oxide

(TLR) Toll-like receptor

(PI3K) phosphatidylinositol 3-kinase

(Akt) Protein kinase B

(LPS) lipopolysaccharide

(IкB) inhibitor kappa Binhibitor кB

(Nrf2) nuclear factor-erythroid 2-related factor 2

(HO) heme oxygenase

(SD) Sprague Dawley

(PPAR- $\gamma$ ) peroxisome proliferator-activated receptor- $\gamma$

(ROS) reactive oxygen species

(MMP) matrix metalloproteinase

(PCNA) proliferating cell nuclear antigen

(CCA) cholangiocarcinoma

(Bcl-2) B-cell lymphoma-2

(mTOR) mammalian target of rapamycin

(PKC) protein kinase C

(VSMC) vascular smooth muscle cell

(NO) nitric oxidenitric oxide

(cGMP) guanosine $3^{\prime}, 5^{\prime}$-cyclic phosphate

(ACE) angiotensin-converting enzyme

(Ang II) angiotensin II

(AT-1R) Ang II type 1 receptor

(FAK) focal adhesion kinase

(MEK) mitogen-activated protein kinase

(eNOS) endothelial nitric oxide synthase

(MES) mouse embryonic stem

(EB) embryoid body

(VEGF) vascular endothelial growth factor

(HIF-1a) hypoxia-inducible factor-1a

(ET-1) endothelin-1

(TNF- $\boldsymbol{\alpha}$ ) tumor necrosis factor- $\alpha$

(PAH) pulmonary arterial hypertension
(DSS) dextran sulfate sodium

(IL-1 $\beta$ ) interleukin-1 $\beta$

(IкB) inhibitor kappa Binhibitor $\kappa \mathrm{B}$

(ICAM-1) intercellular adhesion molecule-1

(Cdk2) cyclin-dependent kinase 2

(IGF-1) insulin-like growth factor-1

(IGFBP-5) IGF-binding protein-5

(IGF-1R) IGF-1 receptor

(MPO) myeloperoxidase

(PKA) protein kinase A

(AD) Alzheimer's disease

(CYP) cytochrome P450 monooxygenase

(SOD) superoxide dismutase

(GSH-Px) glutathione peroxidase

(CORT) corticosterone

(GSH) glutathione

(AA) aristolochic acid

(MIC) minimal inhibitory concentration

(MBC) minimal bactericidal concentration

(SIRT1) silent information regulator 1

(NE) norepinephrine

(BDNF) brain-derived neurotrophic factor

(HPA) hypothalamic-pituitary-adrenal

(5-HT) 5-hydroxytryptamine

(4-HNE) 4-hydroxynonenal

(FoxO) O subfamily of forkhead transcription factors

(HASMCs) human aortic smooth muscle cells

(Cdc42) cell division cycle 42

(GSK3 $\beta$ ) glycogen synthase kinase $3 \beta$

(HEK) human embryonic kidney

(I-R) ischemia-reperfusion

(CMS) chronic mild stress

(BBB) blood-brain barrier

(LC50) lethal concentration

(CAT) catalase

(p-JNK) phospho-JNK

(MRSA) methicillin-resistant Staphylococcus aureus

(MSSA) methicillin-susceptible $S$. aureus

(CDC) cell division cycle gene

(PS-630) Povidone S-630

(HPC) hydroxypropyl cellulose

(EPO) Eudragit EPO

(PVP K30) polyvinylpyrrolidone K30 
(CMC) carboxymethylcellulosecroscarmellose sodium

(BMP2) bone morphogenetic protein 2

(RUNX2) runt-related transcription factor 2

(ApoE) apolipoprotein E

(i.v.) intravenous

(i.p.) intraperitoneal

(CMC) carboxymethylcellulosecroscarmellose sodium
(AUC) area under the curve

$\left(T_{1 / 2}\right)$ elimination half-life

$\left(T_{\max }\right)$ maximum concentration-time

$\left(C_{\text {max }}\right)$ maximum concentration

(GBC) gallbladder carcinoma

(TMT) trimethyltin 